\title{
Hand Motor Recovery Following Extensive Frontoparietal Cortical Injury Is Accompanied by Upregulated Corticoreticular Projections in Monkey
}

\author{
늘 Warren G. Darling, ${ }^{1}$ Jizhi Ge, ${ }^{3}$ Kimberly S. Stilwell-Morecraft, ${ }^{3}$ Diane L. Rotella, ${ }^{1}{ }^{\oplus}$ Marc A. Pizzimenti, ${ }^{2}$ \\ and Robert J. Morecraft ${ }^{3}$ \\ ${ }^{1}$ Department of Health and Human Physiology, Motor Control Laboratories, ${ }^{2}$ Department of Anatomy and Cell Biology, Carver College of Medicine, \\ University of Iowa, Iowa City, Iowa 52242, and ${ }^{3}$ Division of Basic Biomedical Sciences, Laboratory of Neurological Sciences, University of South Dakota, \\ Sanford School of Medicine, Vermillion, South Dakota 57069
}

We tested the hypothesis that arm/hand motor recovery after injury of the lateral sensorimotor cortex is associated with upregulation of the corticoreticular projection (CRP) from the supplementary motor cortex (M2) to the gigantocellular reticular nucleus of the medulla (Gi). Three groups of rhesus monkeys of both genders were studied: five controls, four cases with lesions of the arm/hand area of the primary motor cortex (M1) and the lateral premotor cortex (LPMC; F2 lesion group), and five cases with lesions of the arm/hand area of M1, LPMC, S1, and anterior parietal cortex (F2P2 lesion group). CRP strength was assessed using high-resolution anterograde tracers injected into the arm/hand area of M2 and stereology to estimate of the number of synaptic boutons in the Gi. M2 projected bilaterally to the $\mathrm{Gi}$, primarily targeting the medial Gi subsector and, to a lesser extent, lateral, dorsal, and ventral subsectors. Total CRP bouton numbers were similar in controls and F2 lesion cases but F2P2 lesion cases had twice as many boutons as the other two groups ( $p=$ 0.0002). Recovery of reaching and fine hand/digit function was strongly correlated with estimated numbers of CRP boutons in the F2P2 lesion cases. Because we previously showed that F2P2 lesion cases experience decreased strength of the M2 corticospinal projection (CSP), whereas F2 lesion monkeys experienced increased strength of the M2 CSP, these results suggest one mechanism underlying $\mathrm{arm} /$ hand motor recovery after F2P2 injury is upregulation of the M2 CRP. This M2-CRP response may influence an important reticulospinal tract contribution to upper-limb motor recovery following frontoparietal injury.

Key words: arm/hand coordination; middle cerebral artery stroke; motor recovery; pyramidal tract; reticulospinal tract; sensorimotor cortex injury

\section{Significance Statement}

We previously showed that after brain injury affecting the lateral motor cortex controlling arm/hand motor function, recovery is variable and closely associated with increased strength of corticospinal projection (CSP) from an uninjured medial cortical motor area. Hand motor recovery also varies after brain injury affecting the lateral sensorimotor cortex, but medial motor cortex CSP strength decreases and cannot account for recovery. Here we observed that motor recovery following sensorimotor cortex injury is closely associated with increased strength of the descending projection from an uninjured medial cortical motor area to a brainstem reticular nucleus involved in control of arm/hand function, suggesting an enhanced corticoreticular projection may compensate for injury to the sensorimotor cortex to enable recovery of arm/hand motor function.

\section{Introduction}

The mechanisms underlying recovery of upper-limb motor function after damage to the sensorimotor system due to stroke and

Received Feb. 9, 2018; revised May 21, 2018; accepted May 30, 2018.

Author contributions: W.G.D. and R.J.M. designed research; W.G.D., J.G., K.S.S.-M., D.L.R., and R.J.M. performed research; R.J.M. contributed unpublished reagents/analytic tools; W.G.D., J.G., D.L.R., M.A.P., and R.J.M. analyzed data; W.G.D. and R.J.M. wrote the paper.

This work was supported by National Institutes of Health Grants NS 097450 and NS 046367. traumatic brain injury are the focus of considerable research (Nudo, 2013; Baker et al., 2015; Carmichael et al., 2017; Ward, 2017). Because the motor system exhibits parallel distributed

The authors declare no competing financial interests.

Correspondence should be addressed to Dr. Robert J. Morecraft, Division of Basic Biomedical Sciences, Laboratory of Neurological Sciences, University of South Dakota, Sanford School of Medicine, Vermillion, South Dakota 57069 E-mail: Robert.Morecraft@usd.edu.

DOI:10.1523/JNEUROSCI.0403-18.2018

Copyright $\odot 2018$ the authors $\quad 0270-6474 / 18 / 386323-17 \$ 15.00 / 0$ 


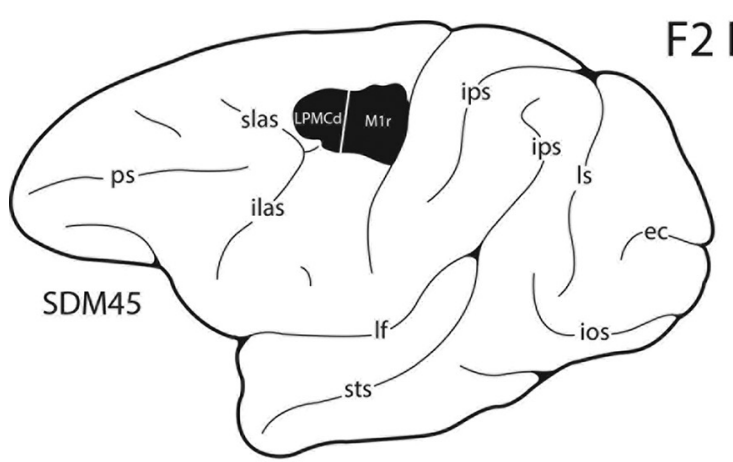

F2 Lesion Cases
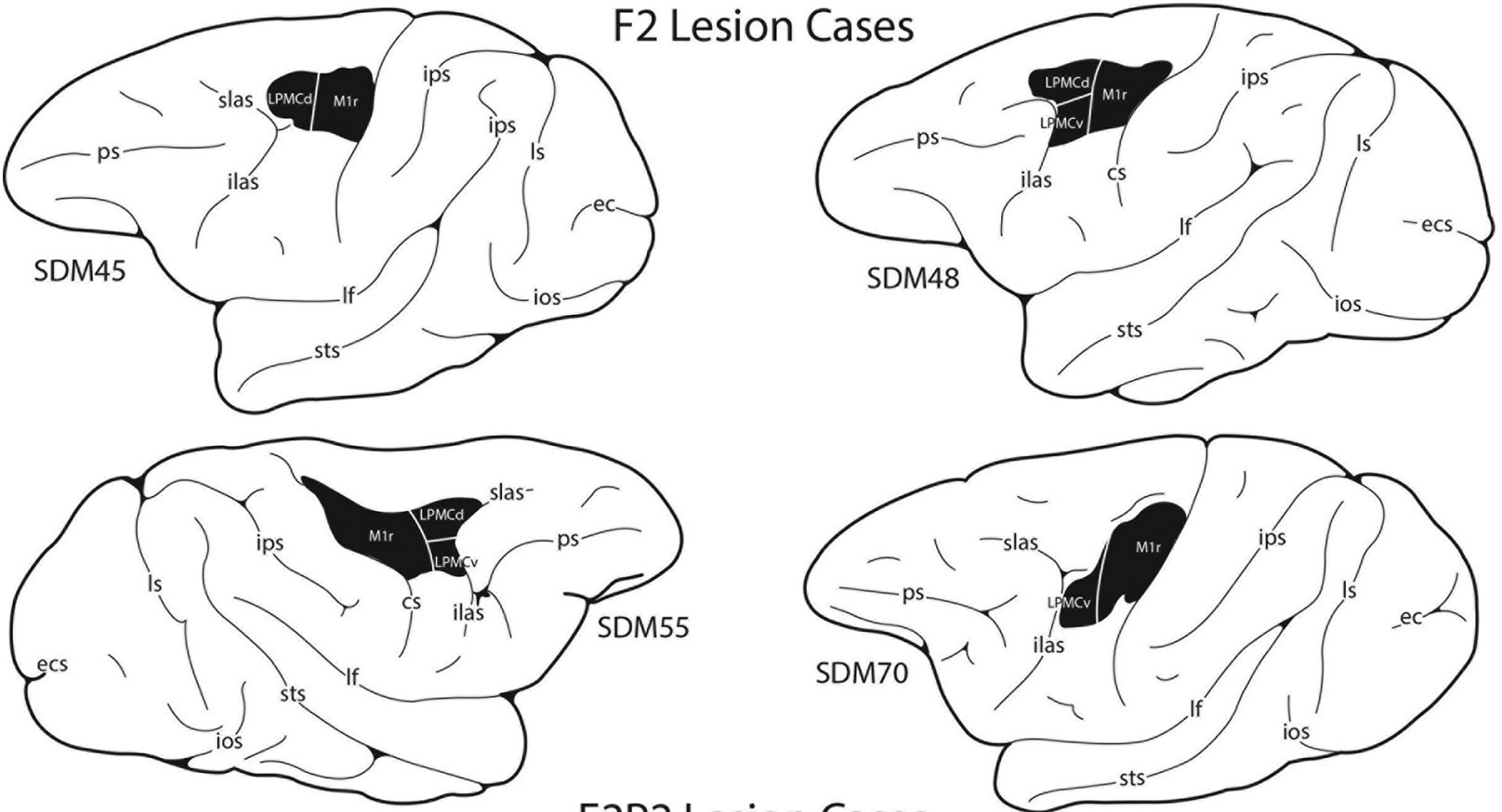

F2P2 Lesion Cases
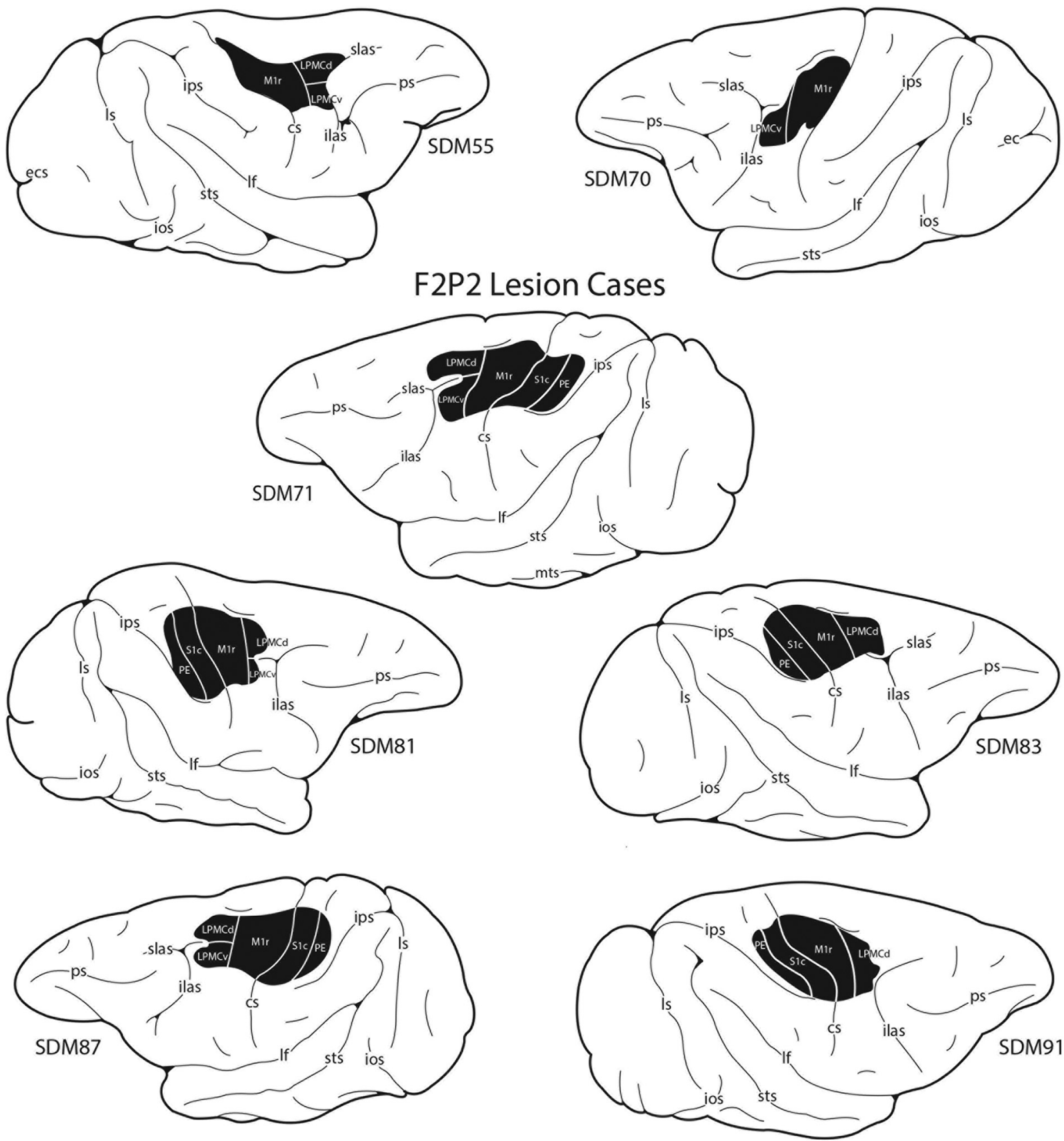

Figure 1. Line drawings of the lateral surface of the injured hemisphere of four cases with F2 lesions (top) and five cases with F2P2 lesions (bottom). For detailed descriptions of the lesion sites, FD injection sites in spared iM2, and affiliated ICMS maps, see McNeal et al. (2010) and Morecraft et al. (2015a, 2016). cs, Central sulcus; ilas, inferior limb of the arcuate sulcus; ios, inferior occipital sulcus; ipcd, inferior precentral dimple; ips, intraparietal sulcus; If, lateral fissure; LPMCd, dorsolateral premotor cortex; LPMCv, ventrolateral premotor cortex; Is, lunate sulcus; M1r, rostral M1; PE, architectonic area of the superior parietal lobule (Pandya and Seltzer, 1982); ps, principle sulcus; S1c, caudal primary somatosensory cortex; SDM, South Dakota Monkey; slas, superior limb of the arcuate sulcus; sts, superior temporal sulcus. 
Table 1. Experimental subjects: characteristics and lesion volumes in $\mathrm{mm}^{3}$ and as a percentage of total volume of the caudal M1 and rostral S1

\begin{tabular}{|c|c|c|c|c|c|c|c|c|c|c|c|c|c|c|c|}
\hline \multirow[b]{4}{*}{ Case } & \multirow{4}{*}{$\begin{array}{l}\mathrm{Age}^{a} \\
\text { (years) }\end{array}$} & \multirow[b]{4}{*}{ Sex } & \multirow{4}{*}{$\begin{array}{l}\text { Handedness } \\
\text { index }^{b}\end{array}$} & \multirow{4}{*}{$\begin{array}{l}\text { Lesion } \\
\text { category }\end{array}$} & \multirow{4}{*}{$\begin{array}{l}\text { Postlesion } \\
\text { duration } \\
\text { for recovery } \\
\text { (months) }\end{array}$} & \multirow{2}{*}{\multicolumn{2}{|c|}{$\begin{array}{l}\text { Gray matter } \\
\text { lesion volume } \\
\mathrm{mm}^{3}\end{array}$}} & \multirow{2}{*}{\multicolumn{2}{|c|}{$\begin{array}{l}\text { White matter } \\
\text { lesion volume } \\
\mathrm{mm}^{3} \\
\end{array}$}} & \multicolumn{6}{|c|}{ Gray matter lesion volume } \\
\hline & & & & & & & & & & \multicolumn{4}{|c|}{ Percentage } & \multicolumn{2}{|l|}{$\mathrm{mm}^{3}$} \\
\hline & & & & & & \multirow{2}{*}{$\begin{array}{l}\text { Frontal } \\
\text { cortex }\end{array}$} & \multirow{2}{*}{$\begin{array}{l}\text { Parietal } \\
\text { cortex }\end{array}$} & \multirow{2}{*}{$\begin{array}{l}\text { Frontal } \\
\text { cortex }\end{array}$} & \multirow{2}{*}{$\begin{array}{l}\text { Parietal } \\
\text { cortex }\end{array}$} & \multicolumn{2}{|l|}{ M1 } & \multicolumn{2}{|l|}{ S1 } & \multirow{2}{*}{$\begin{array}{l}\text { Lateral } \\
\text { premotor cortex }\end{array}$} & \multirow{2}{*}{$\begin{array}{l}\text { Posterior parietal cortex } \\
\text { (rostral area PE) }\end{array}$} \\
\hline & & & & & & & & & & Rostral & Caudal & Rostral & Caudal & & \\
\hline 45 & 4.9 & Male & $21.3 \mathrm{R}$ & $\mathrm{F} 2$ & 6 & 212.6 & 0.0 & 23.02 & 0.0 & 100 & 10.7 & 0.0 & 0.0 & 99.6 & 0.0 \\
\hline 48 & 6.8 & Female & $6.0 \mathrm{R}$ & $\mathrm{F} 2$ & 12 & 220.3 & 0.0 & 23.12 & 0.0 & 100 & 7.7 & 0.0 & 0.0 & 110.7 & 0.0 \\
\hline 55 & 11.8 & Male & $20.0 \mathrm{~L}$ & $\mathrm{~F} 2$ & 12 & 207.7 & 0.0 & 20.51 & 0.0 & 100 & 27.7 & 0.0 & 0.0 & 87.7 & 0.0 \\
\hline 70 & 7.2 & Male & $4.4 \mathrm{R}$ & $\mathrm{F} 2$ & 6 & 143.2 & 0.0 & 7.76 & 0.0 & 96.5 & 6.2 & 0.0 & 0.0 & 52.3 & 0.0 \\
\hline 71 & 8.8 & Male & $53.4 \mathrm{R}$ & $\mathrm{F} 2 \mathrm{P} 2$ & 12 & 191.9 & 105.4 & 22.53 & 8.9 & 100 & 23.0 & 13.0 & 100 & 84.3 & 0.0 \\
\hline 81 & 12 & Female & 63.6L & $\mathrm{F} 2 \mathrm{P} 2$ & 12 & 108.8 & 68.1 & 7.40 & 6.2 & 85.0 & 30.3 & 19.5 & 100 & 34.3 & 14.5 \\
\hline 83 & 3.8 & Female & 91.0L & $\mathrm{F} 2 \mathrm{P} 2$ & 12 & 181.1 & 76.8 & 8.16 & 8.0 & 100 & 50.2 & 34.4 & 100 & 83.6 & 11.4 \\
\hline 87 & 17 & Female & $60.0 \mathrm{R}$ & $\mathrm{F} 2 \mathrm{P} 2$ & 6 & 224.0 & 102.3 & 44.65 & 11.6 & 100 & 46.1 & 24.4 & 100 & 83.7 & 47.7 \\
\hline 91 & 7.8 & Female & $76.0 \mathrm{~L}$ & $\mathrm{~F} 2 \mathrm{P} 2$ & 6 & 192.6 & 76.2 & 46.21 & 6.7 & 100 & 100 & 69.9 & 100 & 39.4 & 7.8 \\
\hline
\end{tabular}

${ }^{a}$ Age at time of lesion.

${ }^{b}$ Percentage of initial reaches and retrievals with preferred hand minus 50, multiplied by 2 (Nudo et al., 1992); R, right hand preferred; L, left hand preferred.

${ }^{C} F 2, M 1+L P M C ; F 2 P 2, M 1+L P M C+S 1+$ rostral area PE.

processing at multiple levels, many CNS injuries directly affect only one region, leaving other regions able to reorganize and perhaps restore control of motor function. Our previous findings provide strong support for this idea. First, we showed that localized lesions to precentral motor areas controlling upper-limb function, specifically the primary motor cortex (M1) and lateral premotor cortex (LPMC; type-F2 lesion), result in an enhanced corticospinal projection (CSP) from the spared ipsilesional M2 (iM2) to contralateral spinal interneurons and motor neurons at C5-T1 (McNeal et al., 2010). Importantly, this greater projection correlated positively with recovery of fine hand motor function, including precision grasp of small objects. Moreover, subsequent iM2 damage after motor recovery from the M1/LPMC lesion partially reinstated the fine hand/digit motor deficit (McNeal et al., 2010). Together, these results strongly suggest that motor recovery after precentral motor cortex damage depends in part on an intact CSP from iM2. Second, we recently observed that damage to the postcentral somatosensory cortex, in addition to precentral motor cortex injury (type-F2P2 lesion), results in deterioration of the intact iM2 CSP to C5-T1 but results in variable levels of recovery of fine motor function in the hand (Morecraft et al., 2015a). Such F2P2 lesions also blocked a favorable upregulated response in the contralesional M1 (cM1) CSP to ipsilateral C5$\mathrm{T} 1$, preventing a CSP contribution to hand motor recovery from cM1 (Morecraft et al., 2016). Thus, macaque monkeys can apparently recover fine motor function, including precision grasp, after severe damage to the lateral sensorimotor cortex. However, the neural mechanisms underlying recovery of hand motor function following F2P2 lesions and iM2 corticospinal terminal degradation are unclear.

Spared cortical projections to brainstem nuclei, which in turn project axons to spinal motor nuclei, provide another potential mechanism for recovery in addition to CSPs from spared motor areas. An excellent candidate system is the corticoreticulospinal system because the reticular nuclei serve as the origin of the reticulospinal tracts and receive descending projections from the motor cortex, including M2 (Jürgens, 1984; Fregosi et al., 2017), which is rarely affected in stroke (Bogousslavsky and Regli, 1990; Carrera et al., 2007). Indeed, it has been clearly demonstrated that the reticulospinal tract projects to forelimb spinal nuclei in primates (Kuypers et al., 1962; Kneisley et al., 1978). Although reticulospinal projections are thought to control primarily proximal limb muscles, recent work has demonstrated some control over distal muscles, including wrist and intrinsic hand muscles (Davidson and Buford, 2006; Riddle et al., 2009; Baker, 2011; Soteropoulos et al., 2012). Thus, great potential exists for a corticoreticulospinal contribution to recovery of arm as well as hand/ digit movements after localized cortical injury (Herbert et al., 2015). It has been suggested that the corticoreticulospinal system may be especially important for recovery of upper-limb motion after extensive brain injuries that induce moderate to severe hemiparesis (Baker, 2011; Baker et al., 2015).

In the present work, we investigated a possible corticoreticular mechanism underlying variable recovery of fine hand/digit motor function in monkeys with frontoparietal (F2P2) lesions. Because we previously observed that monkeys with F2P2 lesions recover some hand function but have a reduced iM2 contralateral CSP (cCSP) (Morecraft et al., 2015a), we hypothesized that these monkeys might have an enhanced iM2 corticoreticular projection (CRP) compared with nonlesioned animals. Furthermore, we reasoned that upper-limb motor recovery would be positively correlated with size of the M2 CRP in terms of synaptic bouton number in F2P2 lesioned monkeys relative to controls. In contrast, we expected that monkeys with precentral motor cortex (F2) lesions would have a similar M2 CRP to intact control monkeys because the enhanced M2 cCSP likely underlies recovery in these monkeys.

\section{Materials and Methods}

All methods used in this study have been presented in detail in previous reports (Darling et al., 2006; Pizzimenti et al., 2007; McNeal et al., 2010; Morecraft et al., 2015a, 2016). We therefore present abbreviated versions here.

Subjects. Fourteen rhesus monkeys (Macaca mulatta) served as subjects for these experiments: five controls (four males), four with frontal lobe lesions (F2 lesions: hand/arm areas of M1 and LPMC) and five with frontoparietal lesions (F2P2 lesions: hand/arm areas of M1, LPMC, S1, including the anterior part of the superior parietal lobule; Fig. 1). Gender, lesion characteristics (gray/white matter lesion volumes), and strength of hand preference of each lesion case are shown in Table 1. Extensive descriptions of the lesions in each monkey have been provided previously (Darling et al., 2009, 2010, 2016; McNeal et al., 2010; Morecraft et al., 2015a, 2016). The experimental procedures applied in all animals were identical, the tissue was processed in the same manner in all cases, and control cases were generated/processed within the same time frame as both groups of lesion cases. For example, control cases SDM41, SDM54, SDM62, and SDM68 were developed/processed during the generation of the F2 lesion cases (SDM45, SDM48, SDM55, and SDM70) and control 

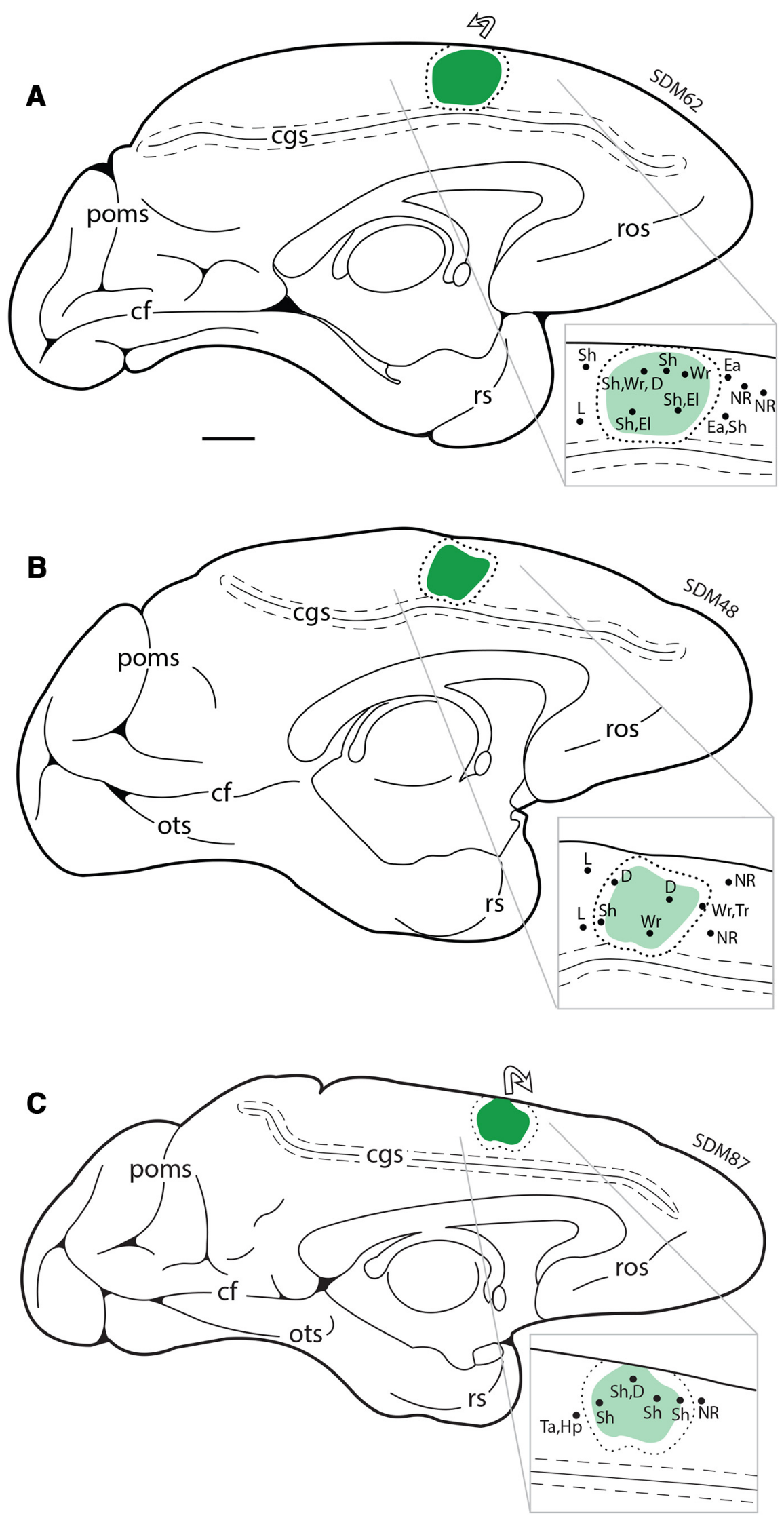

Figure 2. Line drawings of the medial wall of the cerebral cortex in cases SDM62 (control), SDM48 (F2 lesion), and SDM87 (F2P2 lesion) showing the FD injection site located in the physiologically defined arm/hand representation of M2 in the monkey (Macaca mulatta). The injection site core is shown in solid green and the injection site halo is identified by the dotted line surrounding the core region. The curved arrow indicates the extension of the injection site halo onto the dorsolateral crown of the medial frontal cases SDM77 and SDM84 were developed/ processed along with the generation of the F2P2 lesion cases (SDM71, SDM81, SDM83, SDM87, and SDM91). All monkeys were housed at the University of South Dakota and cared for in a facility inspected and approved by the United States Department of Agriculture (USDA) and the Association for Assessment and Accreditation of Laboratory Animal Care. All behavioral, surgical, and experimental protocols were approved by the University of South Dakota Institutional Animal Care and Use Committee and conducted in accordance with USDA, National Institutes of Health, and Society for Neuroscience guidelines for the ethical treatment of animals. Before initiating the study, each monkey was evaluated by a veterinarian with primate experience and judged to be healthy and free of any neurological deficit.

Motor testing. All motor-control testing devices were attached to the animal's cage and the animal was free to move around the cage while performing the motor tests. Monkeys were food-restricted for $18-24 \mathrm{~h}$ before each motortesting session. Initial motor testing established the preferred hand using a standard dexterity board task with 150 trials over a $3 \mathrm{~d}$ period and a hand-preference score was computed based on the number of times each hand was used to acquire small food pellets from wells of various diameters (Nudo et al., 1992). A modified dexterity board $(\mathrm{mDB})$ was used to test fine motor function with testing of each hand controlled by access doors and positioning of the food targets without any restraint on the animal (Pizzimenti et al., 2007). Quantitative 3D video recordings were used to measure duration and accuracy of reaches to the food targets (small food pellets in wells of varying diameters), as well as duration of manipulation and number of times the digit lost contact with the target during manipulation. These measures were also used to compute total, reach (based on duration and accuracy of reach), and manipulation (based on success/failure, duration and number of times the index finger lost contact with the food target) performance score on each trial (Pizzimenti et al., 2007). A modified movement assessment panel (mMAP) was used to assess forces applied during attempts to grasp and manipulate a small food target (carrot chip with central hole for placement on rods attached to the force-measuring device) by each hand, again without any restraint on the animal (Darling et al., 2006). A perfor-

$\leftarrow$

cortex. The inset shows the physiological map of movement representation obtained with intracortical microstimulation to localize the M2 arm/hand representation before injecting FD. Notably, the cortex lining this part of the medial wall of the cerebral cortex is spared in most ( 97\%) stroke patients. cf, Calcarine fissure; cgs, cingulate sulcus; D, digit; Ea, ear; El, elbow; Hp, hip; L, leg, NR, no response; ots, occipital temporal sulcus; poms, medial parieto-occipital sulcus; rs, rhinal sulcus; ros, rostral sulcus; SDM, South Dakota Monkey; Sh, shoulder; Ta, tail; Tr, trunk, Wr, wrist. 

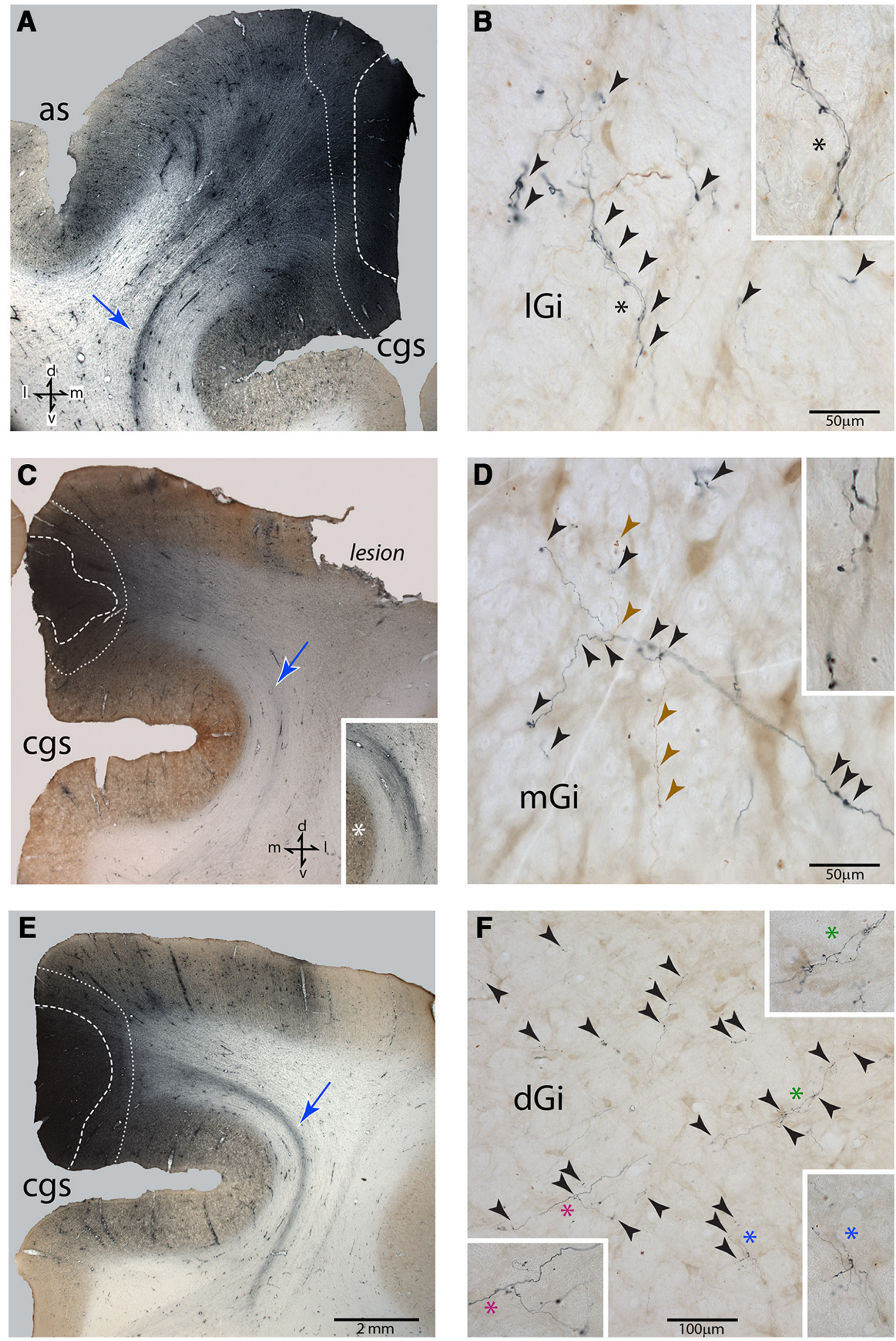

Figure 3. Photomicrographs showing representative examples of the FD injection site in the arm/hand region of $\mathrm{M} 2$ and terminal labeling in the Gi. $A$, Coronal section showing the FD injection site in control case SDM84. The blue arrow identifies a densely coalesced FD-labeled fiber bundle emerging from the injection site and descending toward the internal capsule. Anatomical orientation (bottom left) also applies to $\boldsymbol{B}$ and $\boldsymbol{D}$. B, Horizontal brainstem section showing ipsilateral terminal labeling in the IGi in control case SDM84. The black arrowheads indicate labeled terminal boutons. The inset is a higher-power photomicrograph from the same tissue section (see asterisk in main panel for orientation) showing an intertwined terminal axon field with numerous well defined boutons. C, Coronal section showing the FD injection site in F2 lesion case SDM45. The blue arrow in the main panel identifies a lightly stained FD-labeled fiber bundle emerging from the injection site. A portion of the LPMC lesion can be seen in the upper right region of the tissue section. The inset is from an adjacent coronal section showing a darkly stained portion of the same bundle curving around the depth of the cortex lining the fundus of the cingulate sulcus (asterisk) toward the internal capsule. Anatomical orientation (bottom right) also applies to $\boldsymbol{E}$ and $\boldsymbol{F}$. $\boldsymbol{D}$, Horizontal brainstem section showing contralateral terminal labeling in the mGi in F2 lesion case SDM45. Black arrowheads indicate labeled terminal boutons. The inset is a higher-power photomicrograph from the same tissue section showing FD-labeled terminal boutons in the $\mathrm{mGi}$ subsector. The brown-labeled fibers and boutons (brown arrowheads) are from a BDA injection site placed into another cortical area of interest in case SDM45. E, Coronal section showing the FD injection site in F2P2 lesion case SDM71. The blue arrow identifies a densely coalesced FD-labeled (Figure legend continues.) 
mance score for each trial to acquire the carrot chip from a flat surface and from straight and curved rods (five trials by each hand for each of these tasks representing three levels of difficulty) was computed based on whether acquisition was successful and on manipulation duration and $3 \mathrm{D}$ forces (total absolute impulse) applied during manipulation (Darling et al., 2009).

Neurosurgical and neuroanatomical procedures. The surgical procedures to induce brain lesions and to inject neurotracers were identical to those described previously for F2 lesions (McNeal et al., 2010) and F2P2 lesions (Morecraft et al., 2015a). Briefly, animals receiving lesions were anesthetized with isoflurane for exposure of cortex and then transferred to intravenous ketamine anesthetization for mapping of hand/arm representations of M1 and LPMC (for F2 lesions) or of M1, LPMC, and the anterior parietal cortex (for F2P2 lesions) using intracortical microstimulation (ICMS; Fig. 1). Following somatotopical mapping, each animal was then returned to isoflurane anesthesia and vessels within the hand/arm cortical field were carefully microcauterized. After a 5-10 min coagulation period, the lesion was made using subpial aspiration with the aid of modified Frazier suction tubes (sizes 4, 5, and 6). The craniotomy was closed using standard neurosurgical technique and, after surgery, each animal was administered buprenorphine and penicillin procaine as previously described (McNeal et al., 2010; Morecraft et al., 2015a, 2016). After postoperative recovery, each animal was tested (see above) for 5 or 11 months after the lesion to track motor recovery. Then 30-34 d before terminating the lesion/motor recovery experiment (i.e., transcardiac perfusion), a second surgery was performed to inject the tract tracer into the arm/hand representation of M2 (Fig. 2), which is described below. The controls did not receive cortical lesions, only tract tracer injection in the $\mathrm{M} 2 \mathrm{arm} / \mathrm{hand}$ representation.

To accomplish the neural tracer injections in control and lesion cases, the animals were anesthetized with isoflurane, after which skin and bone flaps and a dural incision were made over the midline region to expose the medial aspect of the frontal lobe. Then, while under ketamine anesthesia, ICMS was used to localize of the arm/hand representation of M2. Once localized, the animal was switched back to isoflurane and the anterograde neural tracer fluorescein dextran (FD) or biotinylated dextran amine (BDA) was injected into the central region of the M2 arm/hand area as described previously (McNeal et al., 2010; Fig. 2). Three equally spaced injections totaling $0.9-1.2 \mu \mathrm{l}$ were made in the central region of the M2 arm/hand representation (McNeal et al., 2010; Morecraft et al., 2015a, 2016). After a 30-34 d survival period to allow for dextran tracer axonal transport, each monkey was deeply anesthetized with an overdose of pentobarbital ( $\geq 50 \mathrm{mg} / \mathrm{kg}$, i.p.) and perfused through the heart with $0.9 \%$ saline followed by $4 \%$ paraformaldehyde and sucrose as previously described (McNeal et al., 2010). The brainstem was blocked (separated) from the diencephalon at a level rostral to the inferior colliculus at a $90^{\circ}$ angle to the long axis of the brainstem (Brodal, 1980; Keizer and Kuypers, 1989; Schmahmann et al., 2004). The cortex was frozen-sectioned in the coronal (frontal) plane and the brainstem frozen-sectioned in the transverse plane, both at a thickness of $50 \mu \mathrm{m}$ and in cycles of 10 . In all cases, one cortical and one brainstem tissue series was processed for cytoarchitectural analysis using Nissl staining procedures as described previously (Morecraft et al., 1992, 2012, 2015b). Additional series of tissue sections were used for immunohistochemical localization of each injected dextran tract tracer as previously described (e.g., BDA + FD; Morecraft et al., 2007a,b, 2015a; McNeal et al., 2010; Fig. 3). Cortical sections through the injection site were analyzed to determine the anatomical location of

$\leftarrow$

(Figure legend continued.) fiber bundle emerging from the injection site and descending toward the internal capsule. The scale bar in the bottom right corner of the panel also applies to $A$ and C. $F$, Horizontal brainstem section showing ipsilateral terminal labeling in the dGi in F2P2 lesion case SDM71. Black arrowheads indicate FD-labeled terminal boutons. The insets all are higherpower photomicrographic images from selected terminal fields of the main panel identified by a matching green, blue, or red asterisk. In $\boldsymbol{A}, \boldsymbol{C}$, and $\boldsymbol{E}$, the white dashed line demarcates the external boundary of the $F D$ injection site core and the white dotted line indicates the external limit of the injection site halo. as, Spur of the arcuate sulcus; cgs, cingulate sulcus; d, dorsal; I, lateral; $m$, medial; $v$, ventral. the injection site, as well as the injection site core and halo volumes as previously described (McNeal et al., 2010; Morecraft et al., 2015a, 2016) and transverse brainstem sections were microscopically evaluated for terminal bouton number (described below).

Gigantocellular reticular nucleus of the medulla: anatomical subdivisions. Several anatomical atlases of the rhesus monkey brain developed for the primary use of stereotaxic application were consulted to locate the general region of the gigantocellular reticular nucleus of the medulla (Gi) and possible subdivisions of the Gi (Snider and Lee, 1961; Martin and Bowden, 2000; Paxinos et al., 2000). However, these atlases do not parcellate the Gi into medial and lateral sectors (only a dorsal, ventral, and centrally located Gi region). In the current report, medial and lateral sectors of the centrally located Gi were identified because it is known that some descending cortical projections preferentially terminate in either the medial or lateral parts of the Gi. Also, the available atlases are prepared in the coronal plane and, as noted, our brainstem tissue sections were prepared in the transverse plane (at a $90^{\circ}$ angle to the long axis of the brainstem). Thus, in the current report, we subdivided the medulla Gi into four anatomical subsectors in the transverse dimension, based upon major reoccurring anatomical landmarks [e.g., medial longitudinal fasciculus (MLF), medial lemniscus (ML), inferior olive (IO), hypoglossal nucleus, intermediate reticular nucleus (IRt), and nucleus ambiguus] and some basic cellular characteristics. Along with a basic description of each Gi subdivision, the general location and rostral-to-caudal boundaries of the medullary Gi are described below.

The rostral-most part of the medullary Gi was located immediately above (e.g., $0.5-1 \mathrm{~mm}$ ) the rostral pole of the hypoglossal nucleus, where the inferior pole of the nucleus prepositus first appears (Fig. $4 A, A^{\prime}$ ). Transverse sections immediately above this level, which included the inferior pole of the facial motor nucleus, were excluded from our quantitative analysis. For the current study, the inferior extent of the Gi coincided with the transverse level just above $(0.5-1 \mathrm{~mm})$ the obex of the fourth ventricle (Sakai et al., 2009; Fig. $4 D, D^{\prime}$ ). Some of the reticular nucleus (Paxinos et al., 2000, their MRt and VRt) does extend caudally from this location, corresponding to transverse sections containing the pyramidal decussation. However, these caudal levels were not included in this study because these nuclei are not classified as the Gi proper (Paxinos et al., 2000).

As noted, before the stereological analysis, the Gi was parcellated into four anatomical subdivisions or subsectors based upon major anatomical landmarks and some cellular characteristics. These included the dorsal, medial, lateral, and ventral Gi subsectors (Fig. $4 A, A^{\prime}$ ). Fusiform and small to medium-sized multipolar cells were located throughout the Gi (Fig. $4 A-D^{\prime}$ ), with large multipolar neurons noted primarily in the dorsal and medial subsectors (Fig. $4 B-C^{\prime}$ ).

The dorsal subsector ( $\mathrm{dGi}$ ) is located directly ventral to the hypoglossal nucleus throughout most of the evaluated part of the medulla (Fig. $4 B-$ $D^{\prime}$ ), with the exception of the superior medulla where the dGi is located ventral to the nucleus prepositus (Fig. $4 A, A^{\prime}$ ). Its medial border coincided with the lateral edge of the MLF and its lateral border coincided with the IRt. Encompassed within the dGi is an aggregate of darkly stained cells identified as the dorsal subdivision of the paramedian reticular nucleus localized by Brodal in the cat (Brodal, 1953; Brodal and Torvik, 1954) and by Somana and Walberg in the monkey (Somana and Walberg, 1978; Fig. $4 B-D^{\prime}$ ). In the monkey, Somana and Walberg describe the cells of the dorsal subdivision as being continuous with the ventral subdivision of the paramedian reticular nucleus (discussed below), located medial to the hypoglossal nerve rootlets (Fig. $4 B^{\prime}-D^{\prime}$, asterisk), and being primarily composed of large neurons with fewer small and medium-sized neurons dispersed between the large cells.

The medial subsector of the $\mathrm{Gi}(\mathrm{mGi}$ ) is located lateral to the MLF and tectospinal tract, ventral to the dGi and IRt, medial to the lateral subsector $(1 \mathrm{Gi})$, and dorsal to the IO (Fig. $\left.4 A-D^{\prime}\right)$. This subsector contained small and medium-size neurons with some large multipolar neurons dispersed in the medial and central region of the $\mathrm{mGi}$ (Fig. $4 B-C^{\prime}$ ). The medial part of the mGi contains the ventral subdivision of the paramedian reticular nucleus (Fig. $4 B-D^{\prime}$ ) identified by Brodal in the cat (Brodal, 1953; Brodal and Torvik, 1954) and by Somana and Walberg in the monkey (Somana and Walberg, 1978). According to Somana and 

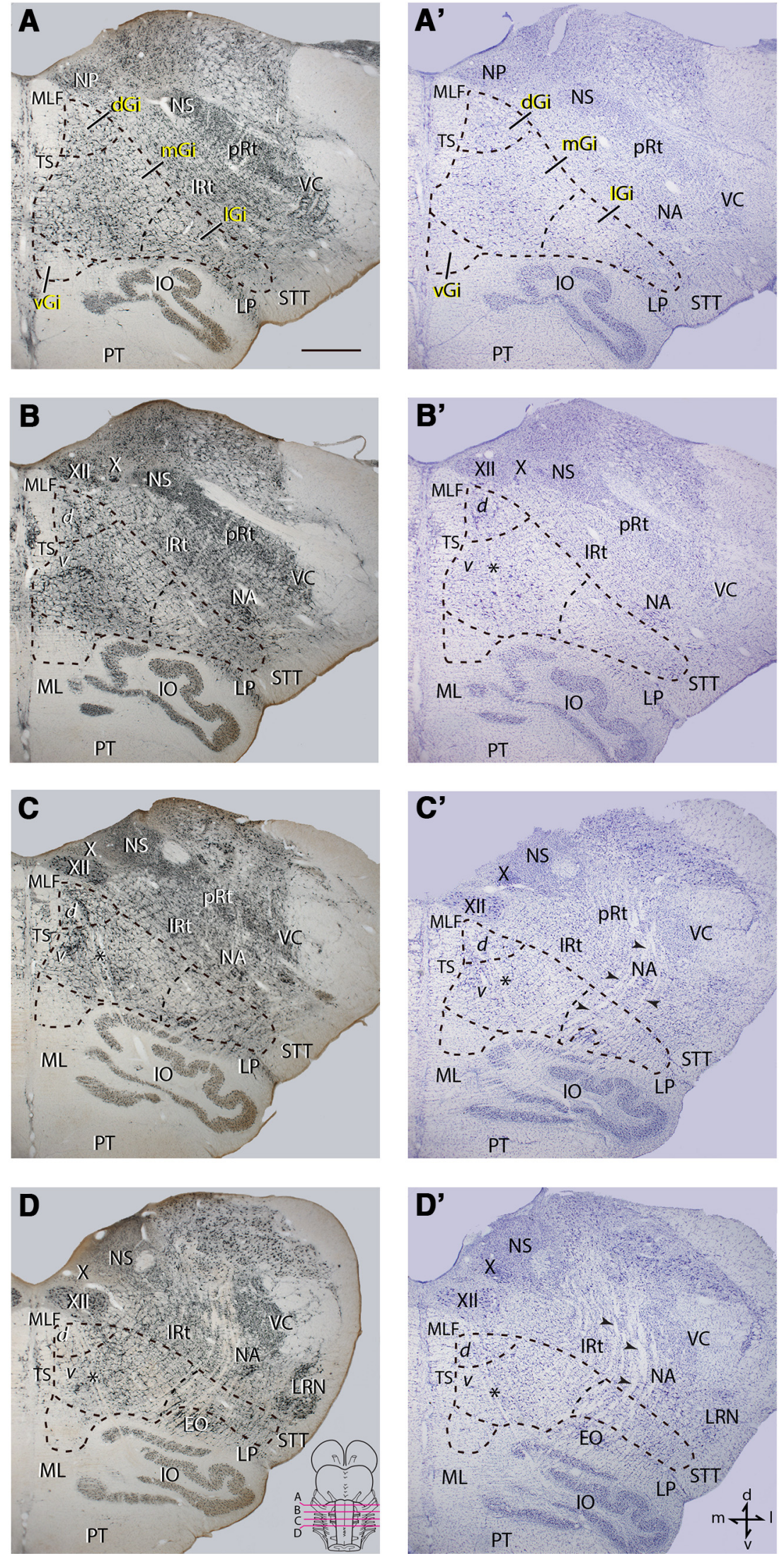

Figure 4. $\quad A-D^{\prime}$, Rostral $\left(A, A^{\prime}\right)$ to caudal $\left(D^{\prime}, D^{\prime}\right)$ series of matching NeuN-stained $(A, B, C, D)$ and Nissl-stained $\left(\boldsymbol{A}^{\prime}, \boldsymbol{B}^{\prime}, \boldsymbol{C}^{\prime}, \boldsymbol{D}^{\prime}\right)$ tissue sections through brainstem levels containing the Gi in Macaca mulatta. The abbreviations for the Gi subdivisions are highlighted in yellow in $\boldsymbol{A}$ and $\boldsymbol{A}^{\prime}$ and apply to all panels below. The black asterisk identifies the emerging root fibers of the hypoglossal nerve. The black arrowheads in $\boldsymbol{C}^{\prime}$ and $\boldsymbol{D}^{\prime}$ identify portions of the internal arcuate fibers. Scalebar, $1 \mathrm{~mm}$. The
Walberg, the ventral subdivision is formed by large, medium-size, and small neurons and lies medial to hypoglossal rootlets (Fig. $4 B^{\prime}-D^{\prime}$, asterisks indicate hypoglossal fibers). Notably, both the dorsal subdivision of the paramedian reticular nucleus and the ventral subdivision project to the cerebellum (Brodal, 1953; Brodal and Torvik, 1954; Somana and Walberg, 1978).

The IGi is located dorsal to the IO (Fig. 4A$\left.D^{\prime}\right)$ and, at lower medullary levels, dorsal to the IO, epiolivary subdivision of the lateral reticular nucleus, and lateral paragigantocellular nucleus (Fig. $4 B-D^{\prime}$ ). It is located ventral to the IRt and the darkly stained cluster of cells forming the nucleus ambiguus (Fig. $4 B-D$ ). Its lateral border included the spinothalamic tract and, at inferior levels of the medulla, the lateral reticular nucleus (Fig. 4D, $D^{\prime}$ ). The medial border of the $\mathrm{lGi}$ is adjacent to the lateral edge of the mGi. Compared with $\mathrm{mGi}$, fusiform and multipolar cells are smaller and less dense and this characteristic can be used to differentiate the $\mathrm{mGi}$ from the $\mathrm{GGi}$, at a location just medial to the dorsal midpoint of the IO (Fig. $4 A-D^{\prime}$ ). At lower levels, cells in the lGi occasionally appear as curvilinear columns due to the presence of internal arcuate fibers (Fig. $4 C-D^{\prime}$, arrowheads) and olivocerebellar fibers, which pass through the lGi en route to their respective target structures.

The ventral subsector (vGi), which occupies the remainder of the medullary $\mathrm{Gi}$, is bounded medially by the paramedian portion of the ML, ventrally by the ML, laterally by the $\mathrm{IO}$, and dorsally by the $\mathrm{mGi}$ (Fig. $4 A-D^{\prime}$ ). The vGi is cell sparse with most cells occurring in the dorsal region of the subsector. We extended the ventral boundary of the vGi to include a small portion of the ML because NeuN tissue sections demonstrated the presence of scattered neurons in this location flattened between ascending ML fiber bundles, and we occasionally noted terminal boutons in this vicinity.

Stereological analysis. Using stereological techniques, transverse brainstem sections spanning the $\mathrm{Gi}$ in the medulla were analyzed to estimate the number of terminal boutons from the M2 CRP in controls and from iM2 CRP in lesioned cases. Terminal bouton number in the ipsilateral and contralateral medullary Gi subsectors were estimated using brightfield microscopy and unbiased stereological counting methods (Glaser and Glaser, 2000; West, 2012). The methods used to calculate terminal bouton numbers are the same as those described in de-

\footnotetext{
schematic drawing of the brainstem in $\boldsymbol{D}$ shows the corresponding transverse level of each section. Anatomical orientation in the bottom right corner of $\boldsymbol{D}^{\prime}$ applies to all panels. $d$, Dorsal; $d$, dorsal subdivision of the paramedian reticular nucleus of Brodal; I, lateral; LP, lateral paragigantocellular reticular nucleus; m, medial; NA, nucleus ambiguus; NP, nucleus prepositus; $\mathrm{NS}$, nucleus of the tractus solitarius; $\mathrm{PT}$, pyramidal tract; pRt, parvicellular reticular nucleus; ST, spinothalamic tract; SV, spinal trigeminal complex (nucleus and tract); $T$, tectospinal tract; $\mathrm{V}$, ventral; $v$, ventral subdivision of the paramedian nucleus of $B$ rodal; $V C$ spinal trigeminal complex. IRt, intermediate reticular nucleus.
} 
Table 2. Bouton counts in each control case by anatomical subsector within the contralateral and ipsilateral Gi

\begin{tabular}{|c|c|c|c|c|c|c|c|c|c|c|c|}
\hline \multirow[b]{2}{*}{ Case } & \multirow{2}{*}{$\begin{array}{l}\text { Tracer } \\
\text { (injection volume) }\end{array}$} & \multicolumn{5}{|c|}{ Contralateral projection } & \multicolumn{5}{|c|}{ Ipsilateral projection } \\
\hline & & Dorsal (\%) & Medial (\%) & ${\text { Lateral }(\%)^{a}}$ & Ventral (\%) & Total $(\%)^{b}$ & Dorsal (\%) & Medial $(\%)^{c}$ & Lateral $(\%)^{c}$ & Ventral $(\%)^{c}$ & Total $(\%)^{b}$ \\
\hline 54 & $\mathrm{FD}(1.2 \mu \mathrm{l})$ & $1269(12.1)$ & $7421(71.0)$ & $1757(16.8)$ & $0(0)$ & $10,447(45.3)$ & $488(3.9)$ & $9765(77.5)$ & $2148(17.1)$ & $195(1.5)$ & $12,596(54.7)$ \\
\hline $68^{d}$ & $\mathrm{BDA}(0.6 \mu \mathrm{l})$ & $84(11.1)$ & $5932(77.8)$ & $762(10.0)$ & $84(1.1)$ & 7625 (58.4) & $423(7.8)$ & $3983(73.5)$ & $508(9.4)$ & $508(9.4)$ & 5422 (41.6) \\
\hline 77 & $\mathrm{FD}(1.2 \mu \mathrm{l})$ & $3970(12.9)$ & $22587(73.1)$ & $4146(13.4)$ & $176(0.6)$ & $30,879(50.1)$ & 3617 (11.8) & $21,352(69.5)$ & $4588(14.9)$ & $1147(3.7)$ & $30,704(49.9)$ \\
\hline 82 & $\mathrm{FD}(1.2 \mu \mathrm{l})$ & $1783(15.8)$ & $6042(53.5)$ & $3467(30.7)$ & $0(0)$ & $11,292(58.8)$ & $990(12.5)$ & $5745(72.5)$ & 1089 (13.7) & $99(1.3)$ & 7923 (41.2) \\
\hline 84 & FD $(1.2 \mu \mathrm{l})$ & $1304(24.2)$ & 2435 (45.2) & 1652 (30.6) & $0(0)$ & 5391 (31.6) & 2261 (19.4) & $5827(50.0)$ & 3131 (26.9) & $434(3.7)$ & $11,653(68.4)$ \\
\hline $\operatorname{Mean}^{e}$ & & 2081.5 & 9621.3 & 2755.5 & 52 & $14,502.3$ & 1839 & $10,672.3$ & 2739 & 468.8 & 15,719 \\
\hline
\end{tabular}

${ }^{a}$ Percentage of contralateral boutons among estimated number of boutons.

${ }^{b}$ Percentage of bilateral boutons among estimated number of boutons.

'Percentage of ipsilateral boutons among estimated number of boutons.

${ }^{d}$ Estimated bouton numbers for SDM68 were excluded from the statistical analysis comparisons to F2-lesioned and F2P2-lesioned monkeys because only 2 of the 3 Hamilton syringe penetrations showed evidence of tracer deposit. However, we included this case in the assessment of laterality of the M2 CRP.

${ }^{e}$ Means do not include SDM68.

Table 3. Bouton counts in each F2 lesion case by anatomical subsector within the contralateral and ipsilateral Gi

\begin{tabular}{|c|c|c|c|c|c|c|c|c|c|c|c|}
\hline \multirow[b]{2}{*}{ Case } & \multirow{2}{*}{$\begin{array}{l}\text { Tracer } \\
\text { (injection volume) }\end{array}$} & \multicolumn{5}{|c|}{ Contralateral projection } & \multicolumn{5}{|c|}{ Ipsilateral projection } \\
\hline & & Dorsal $(\%)^{a}$ & Medial $(\%)^{a}$ & Lateral $(\%)^{a}$ & Ventral $(\%)^{a}$ & Total $(\%)^{b}$ & Dorsal $(\%)^{c}$ & Medial $(\%)^{c}$ & Lateral $(\%)^{c}$ & Ventral $(\%)^{c}$ & Total $(\%)^{b}$ \\
\hline 45 & $\mathrm{FD}(0.9 \mu \mathrm{l})$ & 1585 (12.9) & $9326(75.2)$ & 1305 (10.5) & $186(1.5)$ & $12,402(53.6)$ & 1305 (12.2) & $7181(67.0)$ & $2144(20.0)$ & $93(0.9)$ & $10,723(46.4)$ \\
\hline 48 & $\mathrm{FD}(0.9 \mu \mathrm{l})$ & $133(1.5)$ & 7224 (81.8) & 1471 (16.7) & $0(0)$ & $8828(50.8)$ & $0(0)$ & 5485 (64.1) & $2541(29.7)$ & $535(6.2)$ & 8561 (49.2) \\
\hline 55 & $\mathrm{FD}(0.9 \mu \mathrm{l})$ & $94(2.4)$ & 2451 (63.4) & 1225 (31.7) & $94(2.4)$ & 3864 (42.7) & $1131(21.8)$ & 3205 (61.8) & $660(12.7)$ & 188 (3.6) & $5184(57.3)$ \\
\hline 70 & $\mathrm{FD}(0.9 \mu \mathrm{l})$ & $1356(9.6)$ & 11,041 (78.1) & 1452 (10.3) & $290(2.1)$ & $14,139(53.3)$ & $2034(15.8)$ & 9588 (74.4) & $1162(9.0)$ & $96(0.7)$ & $12,880(46.7)$ \\
\hline Mean & & 792 & 7510.5 & 1363.3 & 142.5 & 9808.3 & 1117.5 & 6364.75 & 1626.75 & 228 & 9337 \\
\hline
\end{tabular}

a Percentage of contralateral boutons among estimated number of boutons.

${ }^{b}$ Percentage of bilateral boutons among estimated number of boutons.

'Percentage of ipsilateral boutons among estimated number of boutons.

Table 4. Bouton counts in each F2P2 lesion case by anatomical subsector within the contralateral and ipsilateral Gi

\begin{tabular}{|c|c|c|c|c|c|c|c|c|c|c|c|}
\hline \multirow[b]{2}{*}{ Case } & \multirow{2}{*}{$\begin{array}{l}\text { Tracer } \\
\text { (injection volume) }\end{array}$} & \multicolumn{5}{|c|}{ Contralateral projection } & \multicolumn{5}{|c|}{ Ipsilateral projection } \\
\hline & & Dorsal $(\%)^{a}$ & Medial $(\%)^{a}$ & Lateral $(\%)^{a}$ & Ventral $(\%)^{a}$ & Total $(\%)^{b}$ & Dorsal (\%) & Medial $(\%)^{c}$ & Lateral $(\%)^{c}$ & Ventral $(\%)^{c}$ & Total $(\%)^{b}$ \\
\hline 71 & $\mathrm{FD}(0.9 \mu \mathrm{l})$ & 3857 (12.9) & $20,925(69.8)$ & 3375 (11.3) & $1832(6.1)$ & $29,989(39.5)$ & 4242 (9.2) & $29,603(64.4)$ & $10,414(22.6)$ & 1735 (3.8) & $45,994(60.5)$ \\
\hline 81 & $\mathrm{FD}(0.9 \mu \mathrm{l})$ & $6835(21.8)$ & $21,660(69.0)$ & $2406(7.7)$ & $481(1.5)$ & $31,382(52.5)$ & 4909 (17.3) & $18,002(63.4)$ & 4235 (14.9) & $1251(4.4)$ & $28,397(47.5)$ \\
\hline 83 & $\mathrm{FD}(0.9 \mu \mathrm{l})$ & $4365(10.9)$ & $31,142(77.5)$ & 3977 (9.9) & 679 (1.7) & $40,163(48.6)$ & $2619(6.2)$ & $31,142(73.3)$ & 7567 (17.8) & $1164(2.7)$ & $42,492(51.4)$ \\
\hline 87 & $\mathrm{FD}(0.9 \mu \mathrm{l})$ & $1252(5.7)$ & $17,713(81.2)$ & $2236(10.2)$ & $626(2.9)$ & $21,827(47.1)$ & $2505(10.2)$ & $19,413(79.2)$ & $2505(10.2)$ & $89(0.4)$ & $24,512(52.9)$ \\
\hline 91 & FD $(1.2 \mu \mathrm{l})$ & $1956(25.3)$ & $5601(72.4)$ & $177(2.3)$ & $0(0)$ & 7734 (36.6) & $4178(31.1)$ & $8624(64.2)$ & $533(4.0)$ & $88(0.7)$ & $13,423(63.4)$ \\
\hline Mean & & 3653 & $19,408.2$ & 2434.2 & 723.6 & 26,219 & 3690.6 & $21,356.8$ & 5050.8 & 865.4 & $30,963.6$ \\
\hline
\end{tabular}

a Percentage of contralateral boutons among estimated number of boutons.

${ }^{b}$ Percentage of bilateral boutons among estimated number of boutons.

cPercentage of ipsilateral boutons among estimated number of boutons.

tail in our previous papers for quantifying bouton number in the spinal cord and amygdala (Morecraft et al., 2007a; McNeal et al., 2010). Specifically, estimates of the total number of terminal boutons within each Gi subsector were determined using a $100 \times$ oil objective, the Optical Fractionator Probe, and our Neurolucida-equipped (RRID:SCR_001775) microscope workstations (MBF Bioscience; RRID:SCR_004314). For the current project, the counting frame measured $100 \times 70 \mu \mathrm{m}$ and the spacing interval between counting frames was $300 \times 150 \mu \mathrm{m}$. Estimated bouton numbers were calculated using StereoInvestigator software. Every tissue section through the medulla (spaced $500 \mu \mathrm{m}$ apart) containing the Gi was used for stereological evaluation. Thus, in all subjects six sections were evaluated with the exception of case SDM91, in which five sections were evaluated. Using cortical tissue sections, unbiased estimates of the total injection site volume and core injection site volume were determined using the Cavalieri probe and calculated using StereoInvestigator software as described in our previous reports (Pizzimenti et al., 2007; McNeal et al., 2010).

We did not attempt to normalize the total bouton number estimates to total number of labeled axons in the medullary pyramid as done by others (Fregosi et al., 2017) because axon sprouting was noted in the pyramid of the lesion cases. To control for our terminal bouton estimates, we provide a detailed assessment of the injection site size (total volume) and break this down into the core region volume (effective uptake/transport area) and halo region volume (potential uptake/trans- port area; Fig. 3). Thus, our injection site analysis estimates the amount of cortex containing potential CRP neurons across all experimental cases. This is particularly important in our experimental design since the controls were injected with slightly more tracer volume (Tables 2, 3, 4) so that any upregulated neuroplastic change in the M2 corticofugal projection following lateral cortical brain injury could not be attributed to the injection site involving a greater amount of cortex harboring CRP neurons (Morecraft et al., 2015a, 2016).

The design of our stereological application (e.g., choice of dissector probe for quantifying bouton numbers and injection site volumes, counting frame size, guard zone depth, etc.) and technical issues related to our use of dextran tracers and experimental strategy have been discussed in great detail in our previous papers (McNeal et al., 2010; Morecraft et al., 2013, 2015a, 2016).

Experimental design and statistical analyses. Estimated numbers of terminal boutons were compared among the three groups (controls: four males and one female; F2 lesion: three males, 1 female; F2P2 lesion: four females, one male) using a mixed three-way (group $\times$ side $\times$ region) repeated-measures ANOVA (side and region as repeated measures). SDM68 was excluded from all analyses because of the smaller volume of neurotracer in this case. Specifically, the estimated number of boutons in the contralateral and ipsilateral projection to each of the four Gi subsectors was entered into this analysis. Huynh-Feldt $\varepsilon$ values were examined to determine whether the assumption of sphericity was met when there 


\section{SDM54 Control}
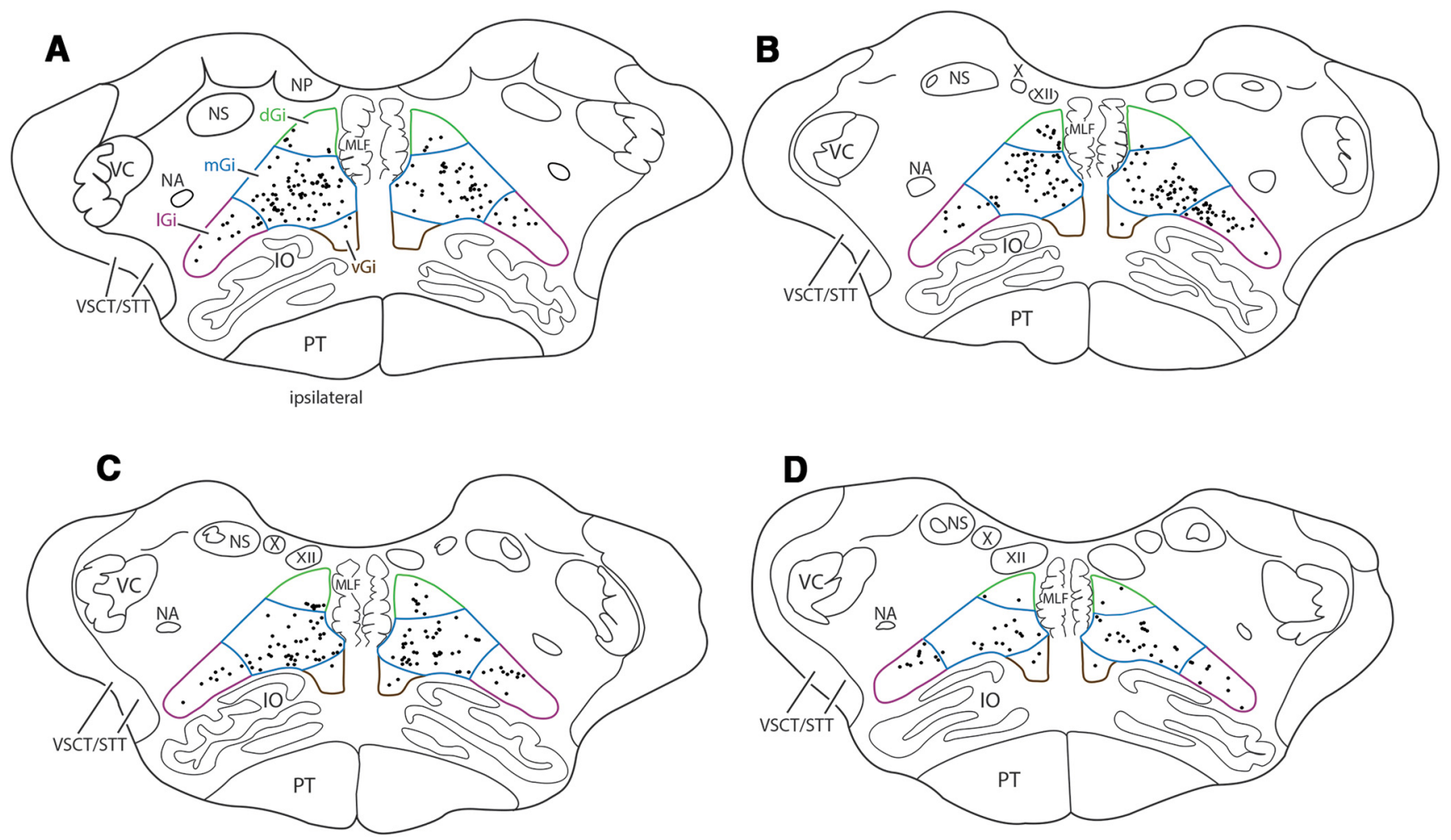

Figure 5. $A-D$, Line drawings of representative horizontal sections from rostral $(\boldsymbol{A})$ to caudal (D) levels of the medulla in control case SDM54 depicting terminal labeling (black dots) in the dGi, $\mathrm{mGi}$, IGi, and vGi following an injection of FD tracer into the arm/hand representation of M2. Note the relatively dense bilateral projection to the mGi subsector. VSCT, Ventral spinocerebellar tract. For other abbreviations, see Figure 4.

were $\geq 3$ levels in a repeated-measures factor (i.e., region) and corrected $p$ values were reported for these effects. Post hoc testing for statistically significant effects identified by the ANOVA was performed using Tukey's HSD procedure. Effect sizes (Cohen's $d$ ) were computed for selected post hoc comparisons based on an uncorrected $t$-test comparison of estimated number of boutons in the two groups. Adjustments in degrees of freedom for $F$ tests were made on the basis of the Huynh-Feldt $\varepsilon$ values, resulting in adjusted $P$ values, which are reported in Results. Statistical tests were accomplished using Statistica software.

Exploratory single linear regression analyses were also performed to determine whether the ratio of estimated number of boutons in individual lesioned animals (in the bilateral iM2 CRP to the medial subsector and in the total bilateral iM2 CRP) to average estimated number of boutons in controls (independent variable) were closely associated with recovery of reach and grasp/manipulation after the lesion (dependent variable). We assessed association of recovery measures with the strength of the bilateral projection rather than unilateral projection because the M2 projection to the Gi was bilateral (see Results) and the reticulospinal projection is also bilateral (Davidson and Buford, 2006; Schepens and Drew, 2006). Associations of recovery measures with the medial subsector and total projections from M2 to the Gi were considered because the medial subsector was the strongest projection and the total projection would include possible contributions from the other subsectors to recovery. The recovery measures used in these analyses were as follows: (1) postlesion weeks until first success and (2) consistent success (on all five trials) in the $\mathrm{mDB}$ and mMAP (curved-rod task); the ratio of highest postlesion skill to prelesion skill in (3) reaching ( $\mathrm{mDB}$ testing: reach performance scores based on duration and accuracy of reaches) and (4) grasp/manipulation (mDB: manipulation performance scores based on success/failure, manipulation duration, and number of times contact between target and digits is lost); and (5) mMAP (manipulation performance scores based on duration and total applied absolute impulse), as described previously (McNeal et al., 2010; Morecraft et al., 2015a).
Briefly, prelesion skill is defined as the mean performance score divided by the SD of performance scores over the last five consecutive motor testing sessions before the lesion. Postlesion skill is defined similarly except that the highest postlesion skill is that observed during five consecutive postlesion testing sessions. We computed $p$ values for one-sided $t$ tests of correlation coefficients because we hypothesized that postlesion duration until first and consistent success would be inversely related to number of boutons and that recovery of skill would be positively correlated with number of boutons. We did not correct $p$ values for multiple regression analyses performed due to the small number of subjects in these exploratory analyses.

\section{Results}

All injection sites resulted in significant terminal labeling in the medullary reticular formation. Histological details of all injection sites, including injection site location, injection site core, and injection site halo have been published (McNeal et al., 2010; Morecraft et al., 2015a) with the exception of control case SDM68 and F2P2 lesion case SDM71. Briefly, the injections for both cases were located in the central region of the physiologically defined $\mathrm{arm} /$ hand area of M2 and involved cortical layers I-VI. Histological evidence of three needle penetrations (from the Hamilton microsyringe) of successfully injected tract tracer (FD) were verified in F2P2 lesion case SDM71 (as with all other previously published M2-injected control and lesioned cases), but only two penetrations of successfully injected tracer (BDA) were found in control case SDM68. This was reflected in the relatively larger core and halo of the FD-injection site in case SDM71 (5.32 and $25.84 \mathrm{~mm}^{3}$ respectively) and in the small injection site core and halo of the BDA-injection site in case SDM68 (1.43 and $8.45 \mathrm{~mm}^{3}$ respectively). Therefore, the results of case SDM71 were used in 


\section{SDM48 F2 Lesion}
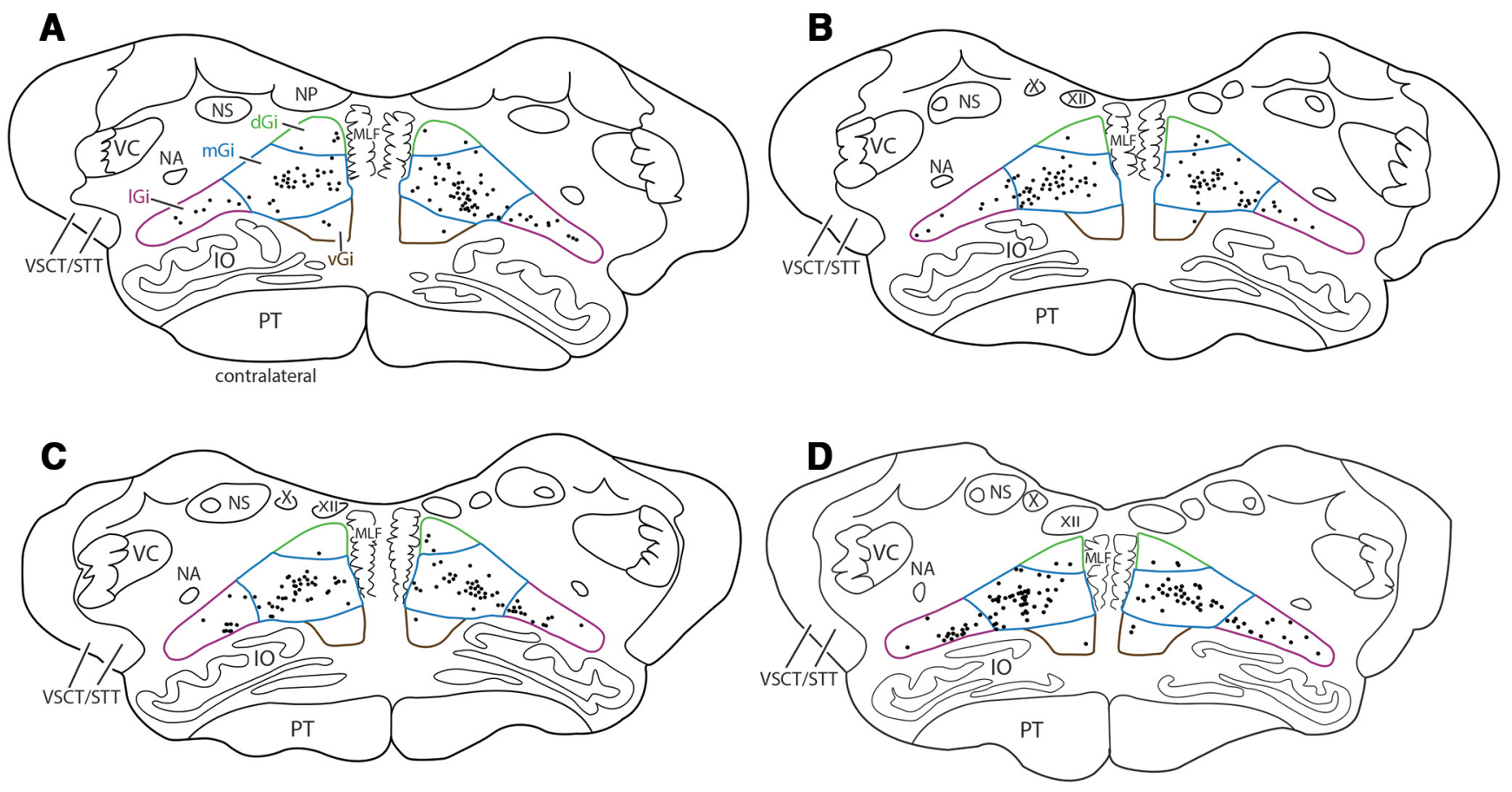

Figure 6. $\boldsymbol{A}-\boldsymbol{D}$, Line drawings of representative horizontal sections from rostral $(\boldsymbol{A})$ to caudal ( $\boldsymbol{D}$ ) levels of the medulla in $\mathrm{F} 2$ lesion case SDM48 depicting terminal labeling (black dots) in the dGi, $\mathrm{mGi}$, IGi, and vGi following an injection of FD tracer into the arm/hand representation of M2. Total numbers of terminal boutons of the CRP for the F2 lesion cases were similar to those of the control cases. For abbreviations, see Figures 4 and 5.

\section{SDM83 F2P2 Lesion}
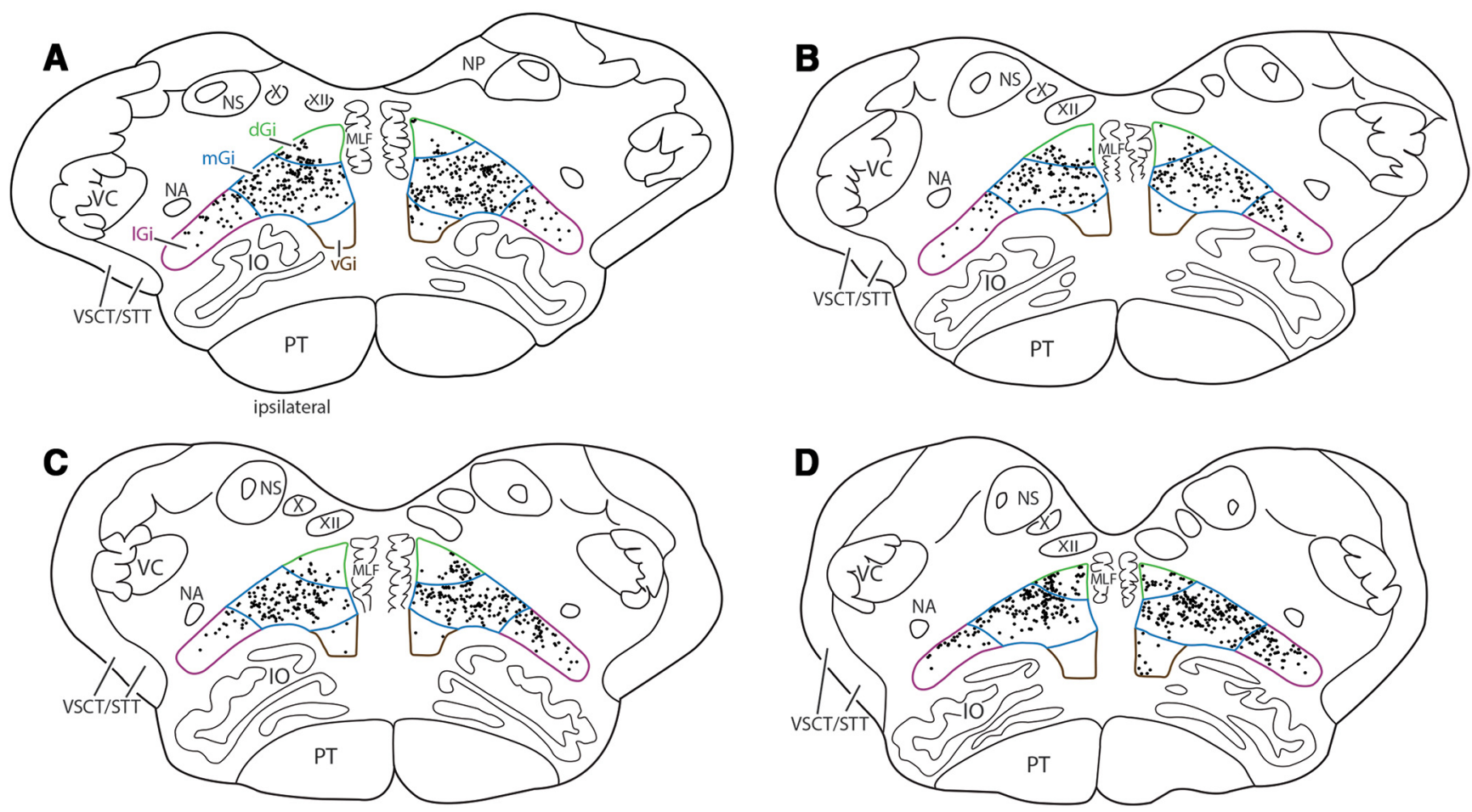

Figure 7. $\boldsymbol{A}-\boldsymbol{D}$, Line drawings of representative horizontal sections from rostral ( $\boldsymbol{A}$ ) to caudal (D) levels of the medulla in F2P2 lesion case SDM83 depicting terminal labeling (black dots) in the $\mathrm{dGi}, \mathrm{mGi}, \mathrm{GG}$, $\mathrm{vGi}$ following an injection of FD tracer into the arm/hand representation of M2. Note the dense bilateral distribution of CRP terminal labeling in the medial Gi subsector as F2P2 cases had approximately twice the number of boutons compared with the controls and F2 lesion cases. For abbreviations, see Figures 4 and 5. 
A

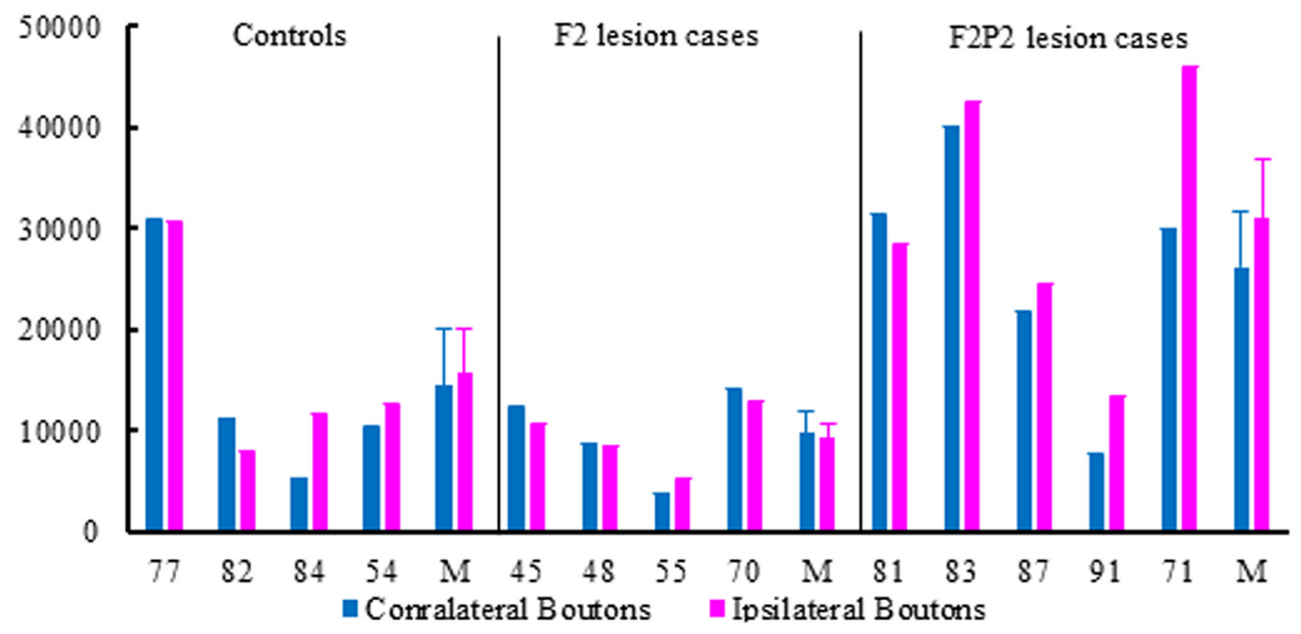

B

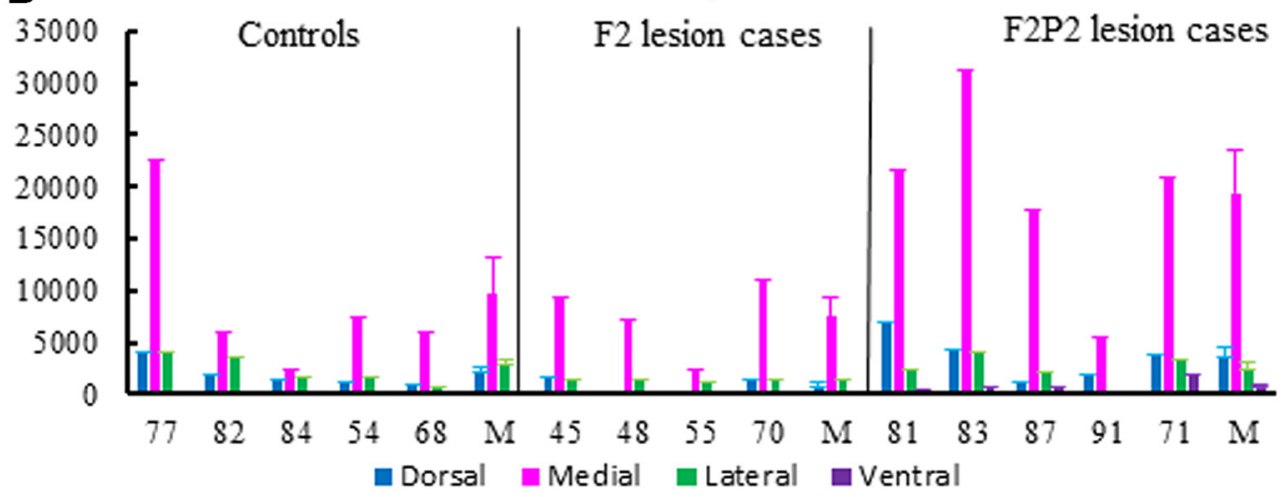

C

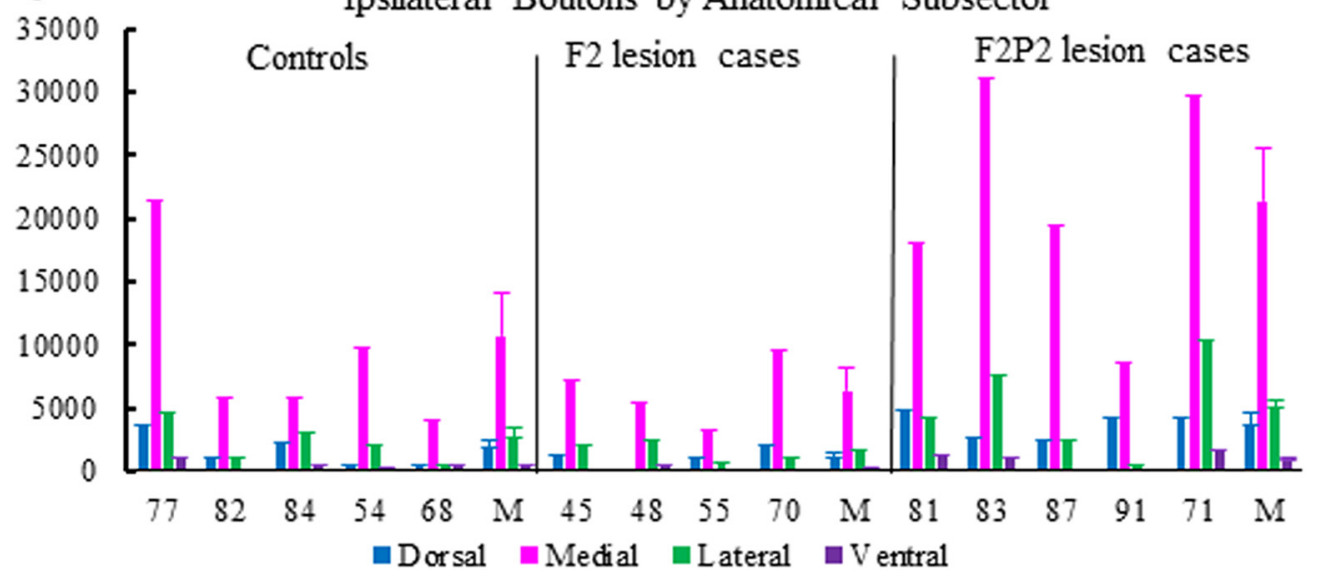

Figure 8. $\quad \boldsymbol{A}-\boldsymbol{C}$, Distribution of boutons in contralateral and ipsilateral $\mathrm{Gi}(\boldsymbol{A})$ and in four different anatomical subsectors of the $\mathrm{Gi}(\boldsymbol{B}, \boldsymbol{C})$. Each bar shows the estimated number of boutons in a single subsector in a single case or the mean (M) of a group (controls, F2 lesion cases, F2P2 lesion cases). Error bars for the mean are 1 SEM.

our lesion analysis/neuroplasticity study design. However, SDM68 was excluded from the control group when making statistical comparisons of estimated bouton numbers against the lesion animal results and was only used for evaluating the general anatomical features of the CRP in control experiments (e.g., topographical distribution of bouton terminals in the four $\mathrm{Gi}$ subsectors and laterality).

In all cases (controls, F2 lesions, and F2P2 lesions), the M2 CRP was bilateral and diffuse, involving all four subsectors of the Gi (Figs. 5-9; Tables 2, 3, 4). Indeed, the contralateral and ipsilat- eral projections were nearly equal in terms of number $\left(F_{(1,10)}=1.71\right.$, $p=0.221)$ and percentage $\left(F_{(1,10)}=1.76, p=0.215\right)$ of estimated boutons in each group and in most subjects (Tables 2, 3, 4; Figs. $8 A, 9$ ), although there were exceptions (e.g., SDM84 of the control group had a much larger ipsilateral projection, as did SDM71 and SDM91 of the F2P2 lesion cases; Fig. 8). In terms of topography, the M2 CRP primarily targeted the $\mathrm{mGi}$ and to a much lesser extent the $\mathrm{lGi}$, dGi, and vGi (Fig. 9). For example, the M2 projection to the $\mathrm{mGi}$ was clearly larger in terms of bouton number than to other Gi subdivisions in all three groups (subsector 

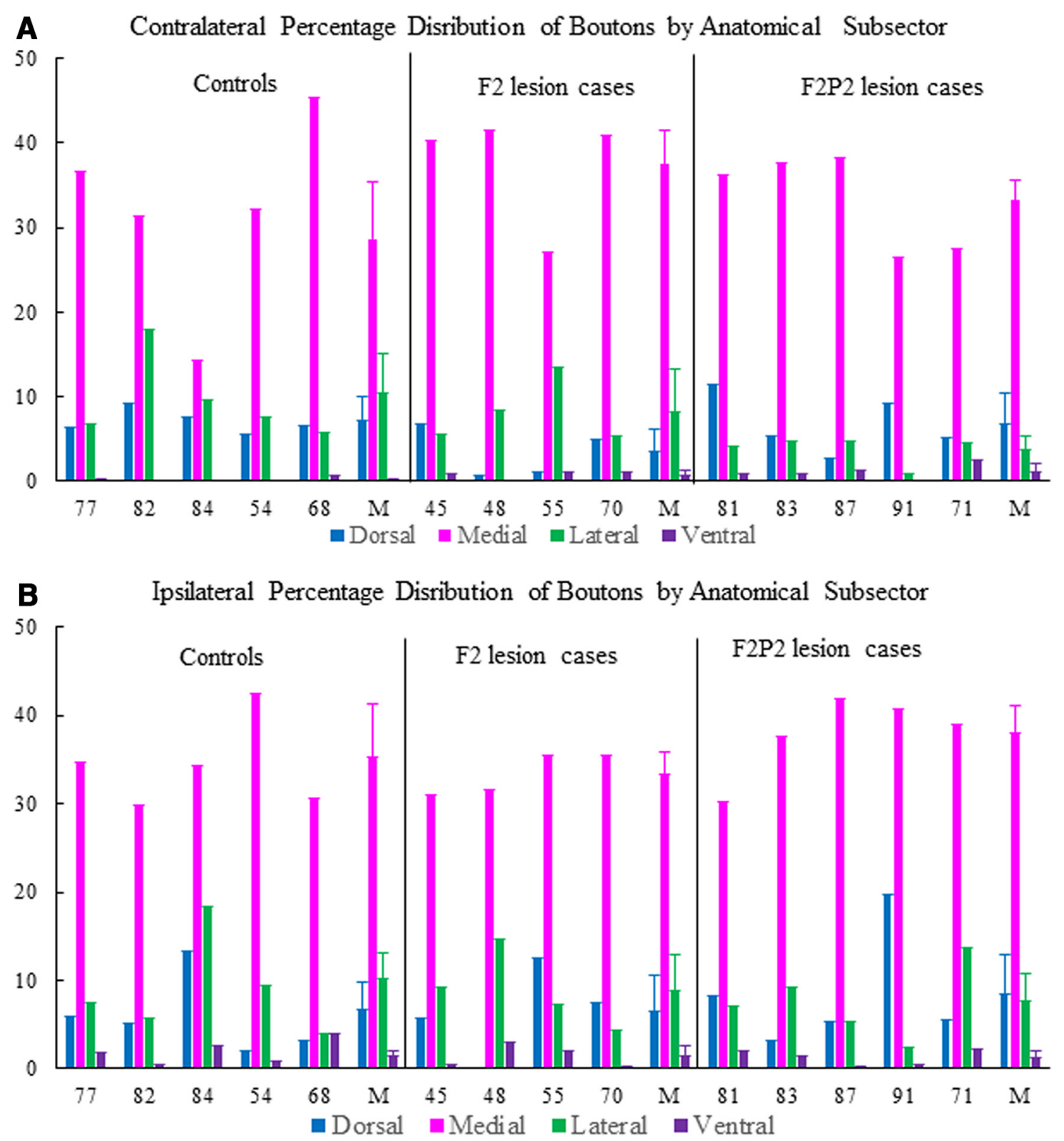

Figure 9. Percentage of all M2-Gi projection boutons by anatomical subsector in the contralateral and ipsilateral Gi. $A, B$, Each bar is the estimated percentage of boutons in a single subsector of the contralateral $(\boldsymbol{A})$ or ipsilateral $(\boldsymbol{B}) \mathrm{Gi}$ for each case and mean $(\mathrm{M})$ for all cases within a group. Error bars for the mean are 1 SEM.

main effect: $F_{(3,30)}=32.86, p=2 \times 10^{-5} ; p=0.0002$ for comparison of $\mathrm{mGi}$ boutons to each of the other three subsectors) and in every control and lesion case (Fig. 8). Finally, in all cases (controls and lesion experiments) the M2 CRP to the dGi and $\mathrm{mGi}$ involved the dorsal and ventral paramedial nuclear regions respectively of Brodal (1953) and Somana and Walberg (1978).

The percentage distribution of terminal boutons from M2 among the four subsectors of the ipsilateral and contralateral Gi was similar among control cases, F2 lesion cases, and F2P2 lesion cases (Fig. 9). Approximately 70-75\% of boutons of the M2 projection were in the medial subsector of the bilateral Gi (30-40\% on each side). Much lower percentages of boutons were in the other three subsectors, with the vGi having the lowest percentage of boutons in all cases.

Lesions to M1 and LPMC (type-F2 lesion) had little effect on the M2 projection to the Gi bilaterally but lesions to M1, LPMC, $\mathrm{S} 1$, and anterior parietal lobe (type-F2P2 lesion) resulted in large increases in the projection, especially to the mGi. This is clearly shown in examples of terminal labeling in the Gi density plots (Figs. 5-7) and in the bar graphs of Figure 8. Statistical analysis confirmed this as there was a significant group $\times$ region interaction effect $\left(F_{(6,30)}=3.76, p=0.040\right)$. Post hoc tests also showed significance ( $p=0.0004,0.0001$ respectively) for comparison of medial subsector boutons of F2P2 cases with controls and F2 lesion cases (effect sizes for uncorrected $t$ test comparisons of groups: 1.80 for comparison of F2P2 lesion cases to controls; 3.12 for comparison of F2P2 lesion cases to F2 lesion cases). F2 lesion cases averaged fewer $\mathrm{mGi}$ boutons than controls but there was no statistical difference on the post hoc test ( $p=0.998$; effect size for uncorrected $t$ test comparison of groups, 0.74 ). All F2P2 lesion monkeys except SDM91 (the case with the worst hand motor function recovery following the F2P2 lesion and largest M1c/S1r lesion; see below) had higher numbers of boutons in the $\mathrm{mGi}$ than the average numbers of boutons for the control and F2 lesion groups (Fig. 8). 

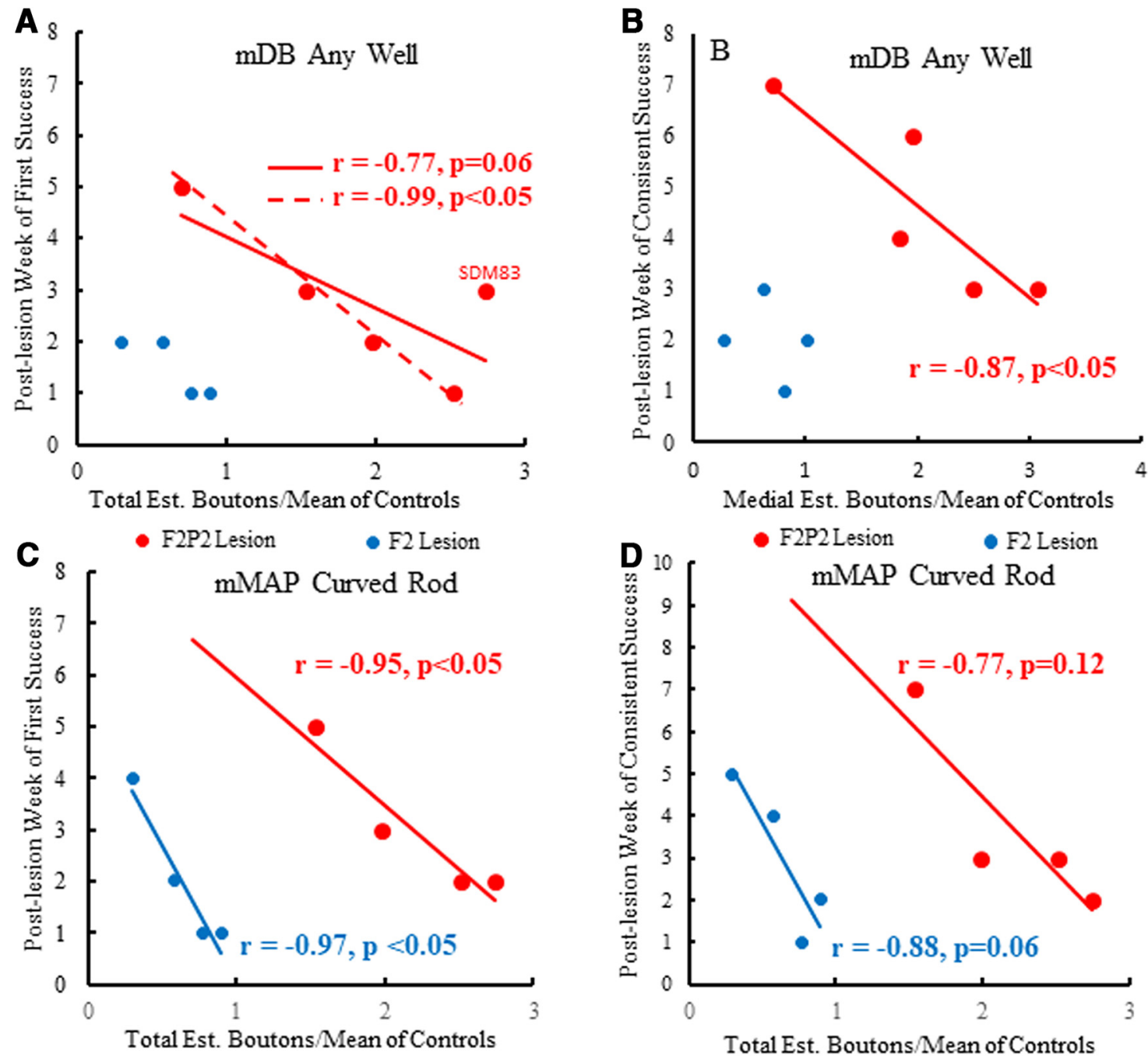

Figure 10. $\quad A-D$, Scatterplots showing relationships between postlesion week of first successful acquisition in the mDB task and total estimated number of boutons in the iM2-Gi bilateral projection ( $\boldsymbol{A}$ ); consistent successful acquisitions (on 5 consecutive trials) in the mDB task and estimated number of boutons in the iM2-Gi bilateral projection to the medial subsector ( $\boldsymbol{B}$ ); postlesion week of first successful acquisition in the mMAP curved-rod task and total estimated number of boutons in the iM2-Gi bilateral projection (C); and postlesion week of consistent successful acquisitions in the mMAP curved-rod task and total estimated number of boutons in the iM2-Gi bilateral projection (D). Each plotted point represents data from a single F2 or F2P2 lesion case. Correlation coefficients and lines of best fit are provided. The solid line in $\boldsymbol{A}$ is for all F2P2 cases and the dashed line excludes SDM83. Note that data from SDM91 is not included in $\boldsymbol{C}$ and $\boldsymbol{D}$ because this case was never successful in the mMAP curved-rod task.

Recovery of contralesional arm reaching and fine hand/digit motor function after the lesion was slower and poorer in F2P2 than in F2 lesion cases as reported previously (Morecraft et al., 2015a, 2016; Darling et al., 2016). Notably, one F2P2 lesion case (SDM91) developed learned nonuse after initially recovering to use precision grasp in a medium-sized well of the mDB task, but was never able to successfully perform the mMAP curved-rod task after the lesion. This case also had the weakest M2 projection to the medial zone of the Gi of the F2P2 lesion cases, being similar to the means of control and F2 lesion cases and $<50 \%$ of the estimated number of medial zone boutons in each of the other F2P2 cases.

Linear regression analyses revealed strong associations of early hand motor recovery measures with the estimated numbers of boutons in either the total M2 CRP bilateral projection or the projection to the mGi. Specifically, among F2P2 lesion cases, but not F2 lesion cases, there were inverse relationships between postlesion week of first success (at 1-5 weeks postlesion) and consistent (on all trials of any well) success (at 2-3 weeks postlesion) on any well in the $\mathrm{mDB}$ task with estimated number of bilat- eral boutons in the total M2-Gi projection (Fig. 10A) or in the projection to the $\mathrm{mGi}$ (Fig. 10B) relative to control means. F2P2 lesion cases with much larger estimated numbers of M2-Gi boutons relative to controls after recovery had early success in the $\mathrm{mDB}$ task, whereas those with fewer boutons showed slower recovery. Similarly, in the difficult mMAP curved-rod task there were also inverse relationships between postlesion week of first and consistent success and the total estimated number of boutons in the M2-Gi bilateral projection in both F2 and F2P2 lesion cases, albeit with much higher ratios of estimated numbers of M2-Gi boutons relative to controls in F2P2 lesion cases (Fig. 10C,D).

Interestingly, among the F2 lesion cases, two monkeys that showed relatively early first (at 1 week postlesion) and consistent (at 2 weeks postlesion) success in the mMAP curved-rod task had about the same estimated number of boutons as controls (i.e., ratio of estimated number of boutons to mean of controls was $\sim 1.0$ ) but two F2 lesion cases with clearly fewer boutons than controls (ratios, $<0.7$ ) exhibited slower recovery (Fig. 10C). F2P2 lesion monkeys with early first and consistent success in the mMAP task had $2.3-3 \times$ the number of boutons in the M2-Gi projection as con- 

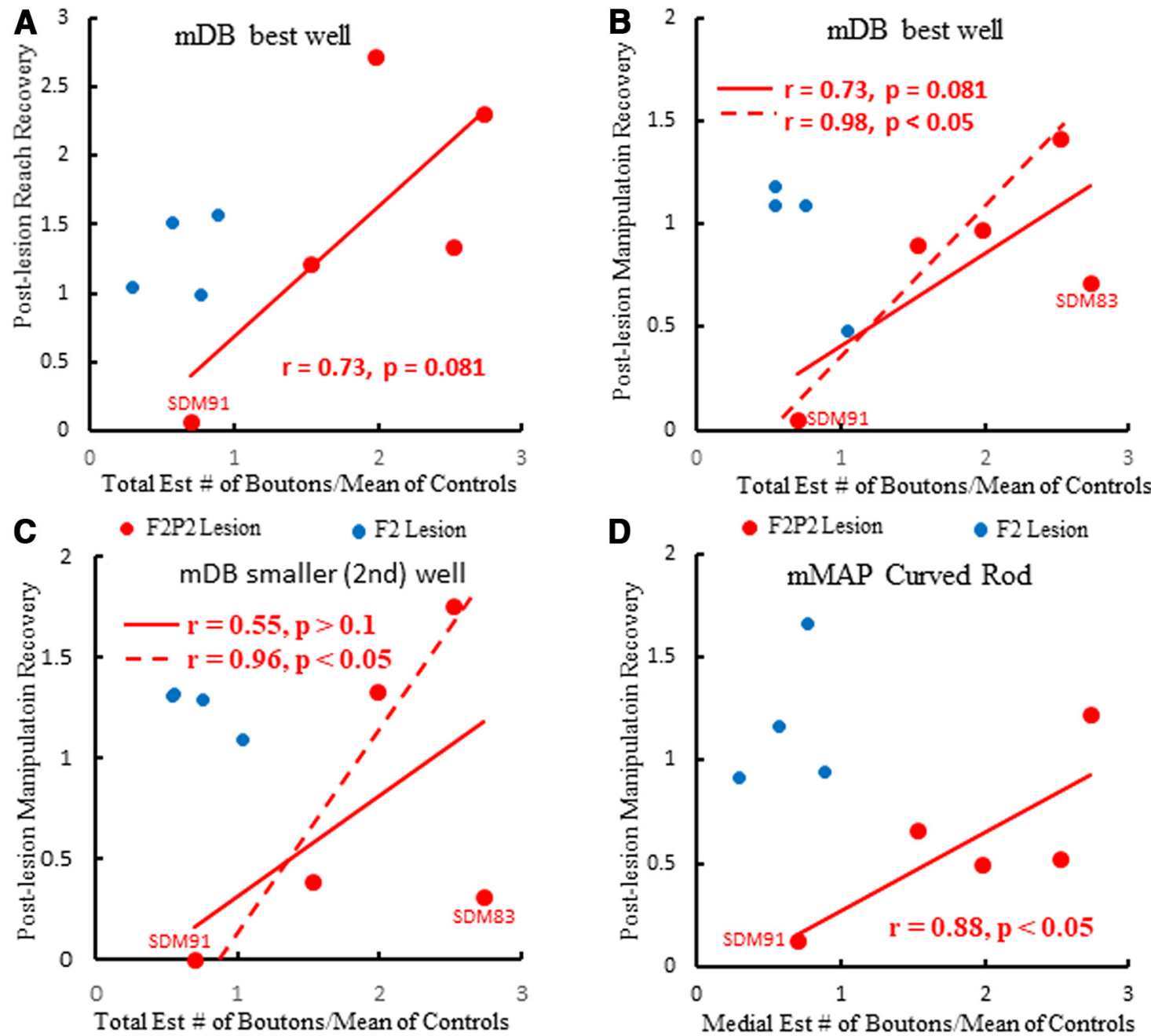

Figure 11. $A-D$, Scatterplots showing relationships between postlesion recovery of reach skill $(\boldsymbol{A})$ in the $\mathrm{mDB}$ task and manipulation skill in the $\mathrm{mDB}$ task $(\boldsymbol{B}, \boldsymbol{C})$ and $\mathrm{mMAP}$ curved-rod task $(\boldsymbol{D})$ with number of boutons in the total iM2-Gi bilateral projection $(\boldsymbol{A}-\boldsymbol{C})$ or in the projection to the medial subsector $(\boldsymbol{D})$. Each plotted point represents data from a single F2 or F2P2 lesion case. Correlation coefficients and lines of best fit are provided for statistically significant relationships $(p<0.05$ ), which in $\boldsymbol{B}$ and C did not include SDM83 of the F2P2 cases (dashed lines), and trends ( $p<$ 0.1 ), which included all five F2P2 cases (solid lines). Note that after the lesion, SDM91 never attempted the small well of the mDB task, leading to a postlesion skill of 0 and only had some unsuccessful attempts on the mMAP curved-rod task, resulting in very low postlesion skill.

trols. It is also important to note that SDM91 is not included in the regression analyses for early recovery on the mMAP curvedrod task because this monkey was never successful at this task and also had fewer total number of boutons than the mean of controls (Fig. 8). SDM91's first success on the easiest mMAP task of picking up a carrot chip from a flat surface occurred 5 weeks after the lesion, which exceeded the other F2P2 lesion cases by 2-4 weeks and the F2 lesion cases by 3-4 weeks. In the mDB task, SDM91 had the slowest early recovery in terms of first ( 5 weeks postlesion) and consistent ( 7 weeks postlesion) success on any well (Fig. $10 A, B)$.

Recovery of reach skill was weakly correlated with estimated numbers of bilateral M2-Gi boutons relative to controls in lesion cases (Fig. 11A), but there were stronger positive associations with recovery of manipulation skill in both $\mathrm{mDB}$ and $\mathrm{mMAP}$ tasks in F2P2 lesion cases, but not in F2 lesion cases (Fig. 10B-D). The positive correlations of estimated number of M2-Gi boutons relative to controls with recovery of manipulation skill are clearly shown in the scatterplots illustrating the positive relationship between recovery of manipulation skill in the $\mathrm{mDB}$ and mMAP curved-rod tasks and estimated number of boutons relative to controls in F2P2 cases, but not in F2 cases (Fig. $11 B-D)$. One
F2P2 lesion case, SDM83, had a relatively poorer recovery of manipulation skill in the mDB task, resulting in much stronger correlations with estimated number of boutons when this case was not included (Fig. $11 B, C$ ), but recovered well in the mMAP curved-rod task, resulting in a strong correlation with all F2P2 lesion cases included (Fig. 11D).

\section{Discussion}

The major results of this report include the following: (1) clear evidence of a bilateral projection from M2 arm/hand area to the Gi in intact/control macaques, (2) the finding that the M2 projection is distributed primarily to the mGi in controls, (3) proof that unilateral frontoparietal sensorimotor area lesions greatly increase the strength of the M2-Gi projection but unilateral frontal lobe motor area lesions do not (Fig. 12), and (4) confirmation that the percentage distribution of boutons in the different $\mathrm{Gi}$ subsectors is unchanged by such lesions.

Previous studies in the monkey have shown that M2 projects bilaterally to the medial part of the lower brainstem reticular formation (Jürgens, 1984; Fregosi et al., 2017), with Fregosi and colleagues reporting one animal with an ipsilateral predominance. Our findings support the strong bilateral nature of the CRP from 

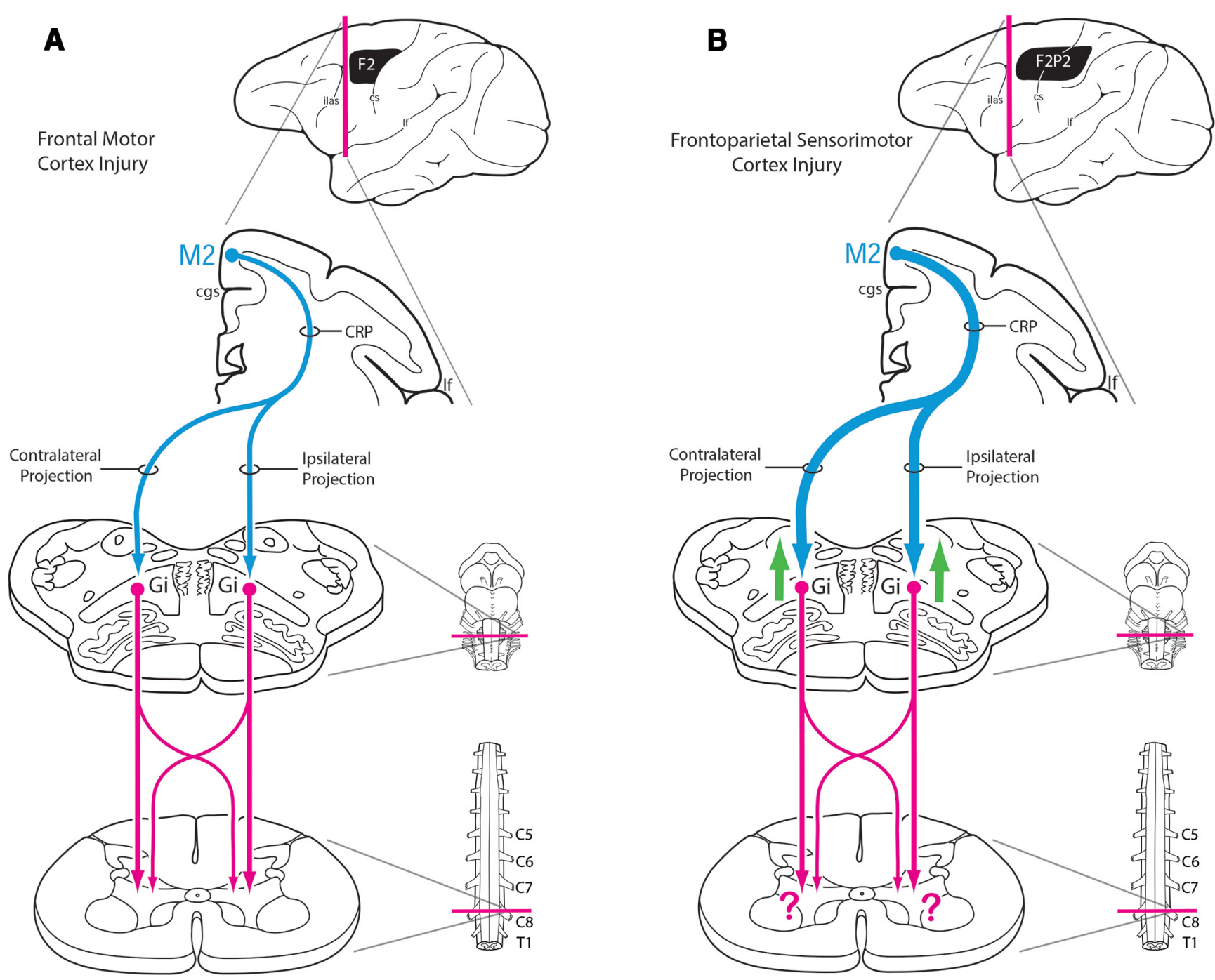

Figure 12. Diagrammatic representation summarizing the results of the present study. $A,(R P$ from the arm/hand region of $M 2$ to the Gi in cases with lateral frontal motor injury (F2 lesion) was found to be bilateral and similar in strength to the control subjects. Importantly, in our other study we found the M2 CSP in these same subjects to be upregulated and correlated to recovery of arm and hand motor movements (McNeal et al., 2010). B, The M2 CRP in cases with frontoparietal injury (F2P2 lesion) increased substantially (i.e., nearly double; see thickened blue descending CRP pathway and green arrows) compared with controls and F2-lesioned cases. Notably, in our previous study we found the M2 CSP in these same F2P2-lesioned subjects to be downregulated (Morecraft et al., 2015a). Thus, it is possible that the enhanced M2 CRP contributed to the variable levels of arm/hand motor recovery that occurred following extensive frontoparietal injury. However, future studies ( $\boldsymbol{B}$, question marks in the spinal cord) will be required to evaluate the response of the reticulospinal projection in this lesion scenario (i.e., F2P2 injury), which is common in patients following middle cerebral artery stroke. cgs, Cingulate sulcus; cs, central sulcus; ilas, inferior limb of the arcuate sulcus; If, lateral fissure.

M2 in controls, and further show that this projection to the Gi in the medulla may be characterized by either an ipsilateral or contralateral predominance, depending upon the individual monkey (Table 2; Fig. 8). Additionally, our observations show, regardless of laterality, that the projection primarily targets the $\mathrm{mGi}$ and, to a much lesser extent, the $\mathrm{lGi}, \mathrm{dGi}$, and vGi. From a topographical perspective, the M2 CRP overlaps with the parts of the medullary reticular formation that have been shown by other groups to give rise to the reticulospinal tract (Kuypers et al., 1962; Kneisley et al., 1978; Sakai et al., 2009; Fregosi et al., 2017) and send projections to the cerebellum (via the paramedian Gi region; Brodal, 1953, 1981; Brodal and Torvik, 1954; Somana and Walberg, 1978).

The finding of a substantial increase in the iM2-Gi projection of F2P2 lesion cases but no change in the projection of F2 lesion cases relative to controls, coupled with our previous reports on the opposite effects of such lesions on the CSP (McNeal et al., 2010; Morecraft et al., 2015a), suggests that a corticoreticular mechanism may support spontaneous arm/hand motor recovery in the
F2P2 lesion cases while a corticospinal mechanism may underlie spontaneous recovery in F2 lesion cases. For example, our previous work showed that the iM2 CSP and cM1 CSP in F2 lesion cases are both upregulated on the severely denervated side of the spinal cord, and the numbers of boutons in those projections correlate positively with arm/hand motor recovery (McNeal et al., 2010; Morecraft et al., 2015a). In contrast, both of these CSPs are downregulated after F2P2 lesions (Morecraft et al., 2015a, 2016), yet all but one of these monkeys (SDM91; discussed below) had good arm/hand recovery with precision grasping of small objects out of small wells (B and/or A) of the mDB (Darling et al., 2016). Therefore, it is likely that the upregulated M2 projection to the $\mathrm{Gi}$ in the F2P2 cases, and possibly other descending projections, such as the red nucleus (Lawrence and Kuypers, 1968) and pontine reticular formation, contribute to this recovery. The positive correlation of recovery of manipulation skill in the mDB and mMAP tasks with the estimated number of boutons in the iM2-Gi projection provides further evidence supporting 
this interpretation. Indeed, reports that stimulation of reticulospinal nuclei and tracts elicit wrist, hand, and finger movements (Davidson and Buford, 2006; Riddle et al., 2009; Soteropoulos et al., 2012), together with the current findings, strongly suggest that enhanced CRPs may contribute to recovery of control over distal muscles necessary for precision grasp and manipulation of small objects after extensive frontoparietal injury. The findings from F2P2 lesion case SDM91 provide additional evidence for this interpretation. Of all the F2P2 lesion cases, SDM91 showed the poorest hand motor recovery and developed learned nonuse of the contralesional hand beginning 9 weeks after the lesion despite early recovery of hand function, including use of precision grasp (Morecraft et al., 2015a; Darling et al., 2016). Among the F2P2 lesion cases, this monkey had the lowest estimated number of boutons in the iM2 CRP, as shown here (Table 4), and lowest estimated number of boutons in the iM2 CSP (Morecraft et al., 2015a) and cM1 CSP (Morecraft et al., 2016) as demonstrated previously. Collectively, these findings strongly support the idea that the CRP from iM2 arm/hand area contributes to upperextremity motor recovery following degradation of the CSP after F2P2 injury. These observations add to the emerging concept that neuroplastic events accompanying recovery following combined frontoparietal/sensorimotor injury differ significantly from the events accompanying recovery after isolated lateral frontal/motor injury (McNeal et al., 2010; Morecraft et al., 2015a, 2016).

Additional evidence for the potential importance of the M2-Gi projection in arm/hand motor function recovery is the findings of inverse relationships between number of boutons in the M2-Gi projection after recovery and postlesion week of first and consistent successes in the mDB and mMAP tasks in F2P2 lesion cases (Fig. $10)$. That is, F2P2 lesion cases with higher numbers of boutons after 6-12 months of recovery exhibited good hand function sooner than other F2P2 cases. For example, SDM83 and SDM71 had consistent successful acquisition on at least one well in the $\mathrm{mDB}$ task at 3 weeks postlesion and, in the mMAP curved-rod task, at 2 and 3 weeks postlesion respectively. These cases also had the highest numbers of boutons in the bilateral $\mathrm{M} 2$ projection to the medial zone of the Gi after recovery (Table 4; Fig. 8A). It is possible that there was a more rapid initiation of increases in the M2-Gi projection in these cases than the other cases. These findings also raise questions related to how soon an increase in strength of the M2-Gi projection is initiated. Indeed, in our study the numbers of boutons could only be established postmortem and after 6 or 12 months of recovery. Thus, the time course over which upregulation of the M2-Gi projection in our experiments is not known. Some previous research in rodents indicates that axonal sprouting to enhance existing connectivity or to establish new connections may begin during the first 4 week postlesion interval (for review, see Wieloch and Nikolich, 2006). Alternatively, these cases may have had a stronger M2-Gi projection before the lesion such that a small postlesion increase in the projection allowed faster recovery.

An intriguing question is why the iM2 CRP and iM2 CSP would respond differently to frontal versus frontoparietal lesions. A possible mechanism is that lesion of the somatosensory area of the anterior parietal lobe removes a large descending projection to the spinal cord (Coulter and Jones, 1977; Ralston and Ralston, 1985; Galea and Darian-Smith, 1994) but would not directly affect the medullary Gi since the anterior parietal cortex does not project to the medullary Gi (Catsman-Berrevoets and Kuypers, 1976; R. J. Morecraft, unpublished observations). Specifically, subtotal removal of parietal cortex CSPs would greatly reduce cortical input to dorsal horn neurons and interneurons involved in hand motor function, potentially disrupting spinal and higher CNS processing of proprioceptive and tactile inputs important for grasp/manipulation of small objects (for review, see Canedo, 1997). This may also result in altered/decreased M2 axon sprouting onto spinal interneurons and motor neurons. In the absence of anterior parietal lobe projections to the $\mathrm{Gi}$, there could be little to no direct effect of the parietal ablation on the Gi neurons. However, the question remains as to why there was no increase in the M2-Gi projection in F2-lesioned monkeys aside from the fact that the CSP is upregulated following F2 injury (McNeal et al., 2010).

In summary, our findings demonstrate that recovery of arm/ hand movements following large lesions involving the periRolandic cortical region (type-F2P2 injury) are accompanied by significant upregulation of the CRP from spared M2 (Fig. 12). This upregulation of terminal boutons may partially compensate for corticospinal degradation that concomitantly occurs in the spared M2 following such injury. Although classical anatomical and behavioral findings suggest the corticoreticulospinal system would support recovery of proximal movements (Lawrence and Kuypers, 1968; Herbert et al., 2015), recent findings showing that reticulospinal projections also have a direct effect on distal upperextremity movements (Davidson and Buford, 2006; Riddle et al., 2009; Baker, 2011; Soteropoulos et al., 2012) indicate that the upregulated CRP may support proximal limb, and possibly unilateral wrist, hand/digit motor recovery. The correlations of CRP bouton proliferation with the variable levels of recovery of contralesional arm and hand/finger grasp and manipulation movements exhibited by the frontoparietal lesion cases presented in this report provide support for this conclusion. Whether therapeutic rehabilitation can induce desirable changes in both the CRP and CSP following peri-Rolandic brain injury remains an open and important question.

\section{References}

Baker SN (2011) The primate reticulospinal tract, hand function and functional recovery. J Physiol 589:5603-5612. CrossRef Medline

Baker SN, Zaaimi B, Fisher KM, Edgley SA, Soteropoulos DS (2015) Pathways mediating functional recovery. Prog Brain Res 218:389-412. CrossRef Medline

Bogousslavsky J, Regli F (1990) Anterior cerebral artery territory infarction in the Lausanne Stroke Registry. Clinical and etiologic patterns. Arch Neurol 47:144-150. CrossRef Medline

Brodal A (1953) Reticulo-cerebellar connections in the cat; an experimental study. J Comp Neurol 98:113-153. CrossRef Medline

Brodal A (1981) Neurological anatomy in relation to clinical medicine, 3 edition. Oxford, UK: Oxford UP.

Brodal A, Torvik A (1954) Cerebellar projection of paramedian reticular nucleus of medulla oblongata in cat. J Neurophysiol 17:484-495. CrossRef Medline

Brodal P (1980) The cortical projection to the nucleus reticularis tegmenti pontis in the rhesus monkey. Exp Brain Res 38:19-27. Medline

Canedo A (1997) Primary motor cortex influences on the descending and ascending systems. Prog Neurobiol 51:287-335. CrossRef Medline

Carmichael ST, Kathirvelu B, Schweppe CA, Nie EH (2017) Molecular, cellular and functional events in axonal sprouting after stroke. Exp Neurol 287:384-394. CrossRef Medline

Carrera E, Maeder-Ingvar M, Rossetti AO, Devuyst G, Bogousslavsky J, Bogousslavsky J (2007) Trends in risk factors, patterns and causes in hospitalized strokes over 25 years: the Lausanne Stroke Registry. Cerebrovasc Dis 24:97-103. CrossRef Medline

Catsman-Berrevoets CE, Kuypers HG (1976) Cells of origin of cortical projections to dorsal column nuclei, spinal cord and bulbar medial reticular formation in the rhesus monkey. Neurosci Lett 3:245-252. CrossRef Medline

Coulter JD, Jones EG (1977) Differential distribution of corticospinal pro- 
jections from individual cytoarchitectonic fields in the monkey. Brain Res 129:335-340. CrossRef Medline

Darling WG, Peterson CR, Herrick JL, McNeal DW, Stilwell-Morecraft KS, Morecraft RJ (2006) Measurement of coordination of object manipulation in non-human primates. J Neurosci Methods 154:38-44. CrossRef Medline

Darling WG, Pizzimenti MA, Rotella DL, Peterson CR, Hynes SM, Ge J, Solon K, McNeal DW, Stilwell-Morecraft KS, Morecraft RJ (2009) Volumetric effects of motor cortex injury on recovery of dexterous movements. Exp Neurol 220:90-108. CrossRef Medline

Darling WG, Pizzimenti MA, Rotella DL, Hynes SM, Ge J, Stilwell-Morecraft KS, Vanadurongvan T, McNeal DW, Solon-Cline KM, Morecraft RJ (2010) Minimal forced use without constraint stimulates spontaneous use of the impaired upper extremity following motor cortex injury. Exp Brain Res 202:529-542. CrossRef Medline

Darling WG, Pizzimenti MA, Rotella DL, Hynes SM, Ge J, Stilwell-Morecraft K, Morecraft RJ (2016) Sensorimotor cortex injury effects on recovery of contralesional dexterous movements in Macaca mulatta. Exp Neurol 281:37-52. CrossRef Medline

Davidson AG, Buford JA (2006) Bilateral actions of the reticulospinal tract on arm and shoulder muscles in the monkey: stimulus triggered averaging. Exp Brain Res 173:25-39. CrossRef Medline

Fregosi M, Contestabile A, Hamadjida A, Rouiller EM (2017) Corticobulbar projections from distinct motor cortical areas to the reticular formation in macaque monkeys. Eur J Neurosci 45:1379-1395. CrossRef Medline

Galea MP, Darian-Smith I (1994) Multiple corticospinal neuron populations in the macaque monkey are specified by their unique cortical origins, spinal terminations, and connections. Cereb Cortex 4:166-194. CrossRef Medline

Glaser JR, Glaser EM (2000) Stereology, morphometry, and mapping: the whole is greater than the sum of its parts. J Chem Neuroanat 20:115-126. CrossRef Medline

Herbert WJ, Powell K, Buford JA (2015) Evidence for a role of the reticulospinal system in recovery of skilled reaching after cortical stroke: initial results from a model of ischemic cortical injury. Exp Brain Res 233:32313251. CrossRef Medline

Jürgens U (1984) The efferent and afferent connections of the supplementary motor area. Brain Res 300:63-81. CrossRef Medline

Keizer K, Kuypers HG (1989) Distribution of corticospinal neurons with collaterals to the lower brain stem reticular formation in monkey (Macaca fascicularis). Exp Brain Res 74:311-318. Medline

Kneisley LW, Biber MP, LaVail JH (1978) A study of the origin of brain stem projections to monkey spinal cord using the retrograde transport method. Exp Neurol 60:116-139. CrossRef Medline

Kuypers HG, Fleming WR, Farinholt JW (1962) Subcorticospinal projections in the rhesus monkey. J Comp Neurol 118:107-137. CrossRef Medline

Lawrence DG, Kuypers HG (1968) The functional organization of the motor system in the monkey. II. The effects of lesions of the descending brain-stem pathways. Brain 91:15-36. CrossRef Medline

Martin RF, Bowden DM (2000) Structure of the macaque brain. New York, NY: Elsevier.

McNeal DW, Darling WG, Ge J, Stilwell-Morecraft KS, Solon KM, Hynes SM, Pizzimenti MA, Rotella DL, Vanadurongvan T, Morecraft RJ (2010) Selective long-term reorganization of the corticospinal projection from the supplementary motor cortex following recovery from lateral motor cortex injury. J Comp Neurol 518:586-621. CrossRef Medline

Morecraft RJ, Geula C, Mesulam MM (1992) Cytoarchitecture and neural afferents of orbitofrontal cortex in the brain of the monkey. J Comp Neurol 323:341-358. CrossRef Medline

Morecraft RJ, McNeal DW, Stilwell-Morecraft KS, Gedney M, Ge J, Schroeder CM, van Hoesen GW (2007a) Amygdala interconnections with the cingulate motor cortex in the rhesus monkey. J Comp Neurol 500:134165. CrossRef Medline

Morecraft RJ, McNeal DW, Stilwell-Morecraft KS, Dvanajscak Z, Ge J, Schneider P (2007b) Localization of arm representation in the cerebral peduncle of the non-human primate. J Comp Neurol 504:149-167. CrossRef Medline
Morecraft RJ, Stilwell-Morecraft KS, Cipolloni PB, Ge J, McNeal DW, Pandya DN (2012) Cytoarchitecture and cortical connections of the anterior cingulate and adjacent somatomotor fields in the rhesus monkey. Brain Res Bull 87:457-497. CrossRef Medline

Morecraft RJ, Ge J, Stilwell-Morecraft KS, McNeal DW, Pizzimenti MA, Darling WG (2013) Terminal distribution of the corticospinal projection from the hand/arm region of the primary motor cortex to the cervical enlargement in rhesus monkey. J Comp Neurol 521:4205-4235. CrossRef Medline

Morecraft RJ, Ge J, Stilwell-Morecraft KS, McNeal DW, Hynes SM, Pizzimenti MA, Rotella DL, Darling WG (2015a) Vulnerability of the medial frontal corticospinal projection accompanies combined lateral frontal and parietal cortex injury in rhesus monkey. J Comp Neurol 523:669697. CrossRef Medline

Morecraft RJ, Stilwell-Morecraft KS, Ge J, Cipolloni PB, Pandya DN (2015b) Cytoarchitecture and cortical connections of the anterior insula and adjacent frontal motor fields in the rhesus monkey. Brain Res Bull 119:5272. CrossRef Medline

Morecraft RJ, Ge J, Stilwell-Morecraft KS, McNeal DW, Hynes SM, Pizzimenti MA, Rotella DL, Darling WG (2016) Frontal and frontoparietal injury differentially affect the ipsilateral corticospinal projection from the nonlesioned hemisphere in monkey (Macaca mulatta). J Comp Neurol 524:380 - 407. CrossRef Medline

Nudo RJ (2013) Recovery after brain injury: mechanisms and principles. Front Hum Neurosci 7:887. CrossRef Medline

Nudo RJ, Jenkins WM, Merzenich MM, Prejean T, Grenda R (1992) Neurophysiological correlates of hand preference in primary motor cortex of adult squirrel monkeys. J Neurosci 12:2918-2947. CrossRef Medline

Pandya DN, Seltzer B (1982) Intrinsic connections and architectonics of posterior parietal cortex in the rhesus monkey. J Comp Neurol 204:196210. CrossRef Medline

Paxinos G, Huang X-F, Toga AW (2000) The rhesus monkey brain in stereotaxic coordinates. New York, NY: Academic.

Pizzimenti MA, Darling WG, Rotella DL, McNeal DW, Herrick JL, Ge J, Stilwell-Morecraft KS, Morecraft RJ (2007) Measurement of reaching kinematics and prehensile dexterity in nonhuman primates. J Neurophysiol 98:1015-1029. CrossRef Medline

Ralston DD, Ralston HJ 3rd (1985) The terminations of corticospinal tract axons in the macaque monkey. J Comp Neurol 242:325-337. CrossRef Medline

Riddle CN, Edgley SA, Baker SN (2009) Direct and indirect connections with upper limb motoneurons from the primate reticulospinal tract. J Neurosci 29:4993-4999. CrossRef Medline

Sakai ST, Davidson AG, Buford JA (2009) Reticulospinal neurons in the pontomedullary reticular formation of the monkey (Macaca fascicularis). Neuroscience 163:1158-1170. CrossRef Medline

Schepens B, Drew T (2006) Descending signals from the pontomedullary reticular formation are bilateral, asymmetric, and gated during reaching movements in the cat. J Neurophysiol 96:2229-2252. CrossRef Medline

Schmahmann JD, Rosene DL, Pandya DN (2004) Motor projections to the basis pontis in rhesus monkey. J Comp Neurol 478:248-268. CrossRef Medline

Snider RS, Lee JC (1961) A stereotaxic atlas of the monkey brain (Macaca mulatta). Chicago, IL: University of Chicago.

Somana R, Walberg F (1978) Cerebellar afferents from the paramedian reticular nucleus studied with retrograde transport of horseradish peroxidase. Anat Embryol (Berl) 154:353-368. CrossRef Medline

Soteropoulos DS, Williams ER, Baker SN (2012) Cells in the monkey pontomedullary reticular formation modulate their activity with slow finger movements. J Physiol 590:4011-4027. CrossRef Medline

Ward NS (2017) Restoring brain function after stroke-bridging the gap between animals and humans. Nat Rev Neurol 13:244-255. CrossRef Medline

West MJ (2012) Introduction to stereology. Cold Spring Harb Protoc 2012: pii:pdb.top070623. CrossRef Medline

Wieloch T, Nikolich K (2006) Mechanisms of neural plasticity following brain injury. Curr Opin Neurobiol 16:258-264. CrossRef Medline 